Review

\title{
Recent Advances in the Synthesis of High Explosive Materials
}

\author{
Jesse J. Sabatini ${ }^{1, *}$ and Karl D. Oyler ${ }^{2, *}$
}

Received: 31 July 2015; Accepted: 22 December 2015; Published: 29 December 2015

Academic Editor: Thomas M. Klapötke

1 US Army Research Laboratory Weapons \& Materials Research Directorate (WMRD) Lethality Division, Energetics Technology Branch, Aberdeen Proving Ground, MD 21005, USA

2 US Army Armaments Research, Development \& Engineering Center (ARDEC) Energetics, Warheads, \& Manufacturing Directorate Explosives Development Branch, Picatinny Arsenal, NJ 07806-5000, USA

* Correspondence: jesse.j.sabatini.civ@mail.mil (J.J.S.); karl.d.oyler.civ@mail.mil (K.D.O.); Tel.: +1-410-278-0235 (J.J.S.); +1-973-724-4784 (K.D.O.)

\begin{abstract}
This review discusses the recent advances in the syntheses of high explosive energetic materials. Syntheses of some relevant modern primary explosives and secondary high explosives, and the sensitivities and properties of these molecules are provided. In addition to the synthesis of such materials, processing improvement and formulating aspects using these ingredients, where applicable, are discussed in detail.
\end{abstract}

Keywords: energetic materials; explosives; synthesis; organic chemistry; processing

\section{Introduction}

There is an ever-increasing need for the development of new energetic materials for explosive applications. This includes, but is not limited to, the area of primary explosives and secondary high explosives. Primary explosives (or "primaries" as they are colloquially called) are defined as energetic materials that possess an exceptionally high initiation sensitivity to impact, friction, electrostatic discharge, heat, and shock. Primaries are known to reach detonation very quickly after such an initiation event. The large amount of energy released upon initiation of a primary-typically in the form of heat or a shockwave-is used to initiate less sensitive energetic materials, including secondary explosives, propellants, and pyrotechnics. Despite their highly sensitive nature, primaries are, in general, less powerful than secondary explosive materials [1]. In other words, primaries typically possess lower detonation velocities, detonation pressures, and a lower heat of detonation than a given secondary explosive. Despite the lower energy of a primary, extreme care is urged when handling these materials.

Primaries are ubiquitous in both military munitions and commercial items, where their main function is to serve as the key ingredient in initiators such as detonators, blasting caps, and pyrotechnic percussion primer formulations. By far, the most commonly used primary explosives by the U.S. military are lead azide (used most often in detonators and blasting caps) and lead styphnate (most often found in percussion primers). There has been significant interest in recent years to develop new primary explosive materials, as the lead content of these materials is highly objectionable from both a toxicological and environmental standpoint [2].

Secondary explosives (colloquially known as "secondaries") differ from primaries in that they are much less sensitive to impact, friction, electrostatic discharge, heat, and shock. Instead, they are intended to be initiated by the heat and shockwave generated from a detonating primary explosive charge. There is a tremendous need for the development of secondary explosives that have higher performance, lower sensitivity, and lower toxicity than the currently fielded explosive compounds. 
Higher performing secondaries are classified as those having higher detonation velocities, higher detonation pressures, higher crystalline densities, and a higher heat of detonation. Secondary explosives with a higher performance typically correlate to an increase in brisance, which is defined as the fragmentation ability or shattering effect of an explosive charge within a specific vicinity. As a rule of thumb, explosives with higher crystal densities and higher enthalpies of formation $\left(\Delta_{\mathrm{f}} H^{0}\right)$ directly correlate to higher detonation pressures, detonation velocities, and overall greater energy release.

Secondaries possessing a lower sensitivity are crucial for the development of insensitive munitions (IM). In the IM sub-area, the development of explosive materials with higher thermal stability and secondary explosive-based formulations that have a low sensitivity to bullet/fragment impact are critical. Minimizing sympathetic detonation - the unintended detonation of a nearby explosive charge which has been caused by a deliberate explosion of another explosive charge, as well as fast- and slow cook-off (the exploding of a munition due to excessive heat in the vicinity) - is key to those interested in IM-based materials. The ideal secondary explosive will have a low toxicity profile of the explosive itself, its degradation products via natural degradation pathways, as well as its detonation products.

Although the field of explosives chemistry has existed for well over a century and produced a wealth of published compounds and their performance data, general literature reviews on explosive compounds [3-5] are relatively small in number and infrequently published. To supplement this list, herein we seek to provide an overview of the more significant recent advances in the area of explosive molecules. This summary is by no means exhaustive, given the wide scope of the explosives field, and the topics covered will focus largely on relatively recently developed compounds which are thought to have the highest likelihood of seeing practical application in the future.

\section{Primary Explosives}

\subsection{Legacy Primary Explosives}

While primary explosives have historically consisted of materials that exhibit reasonable explosive power and a high sensitivity, these legacy materials also possess a high density as a result of the presence of heavy metals within their respective structures. The structures of some historically used primary explosives are given in Figure 1. It is commonly agreed that the highly toxic mercury fulminate (1), adopted for use in some of the first percussion primer formulations in the early 1800s [6] and later by Alfred Nobel for some of the first blasting caps in 1867 [7], is the first primary explosive to see practical application. The high costs associated with mercury, the high sensitivity of mercury fulminate, and its ability to lose performance under high loading pressures paved the way for lead azide (2) to replace the compound starting in the early 1900s [8]. Today, lead azide (including its less sensitive dextrin-coated form) finds wide-ranging application in energetic materials as the main primary explosive ingredient in blasting caps and detonators.

A few years after lead azide began to find applications is the energetics field, the first practical use of lead styphnate was described in a British patent [9]. Lead styphnate comes in two forms; normal lead styphnate (lead(II) 2,4,6-trinitro-benzene-1,3-diolate hydrate) (3) and basic lead styphnate (di(lead(II) hydroxide)-2,4,6-trinitro-benzene-1,3-diolate) (4). Although less powerful than lead azide, lead styphnate is easier to initiate. For this reason, basic lead styphnate is present in some lead azide-based stab detonator formulations such as NOL-130. The use of basic lead styphnate instead of normal lead styphnate in stab detonator mixtures assists in preventing the decomposition of lead azide via a hydrolytic pathway. Normal lead styphnate is commonly encountered as the main primary explosive ingredient in primer applications. 


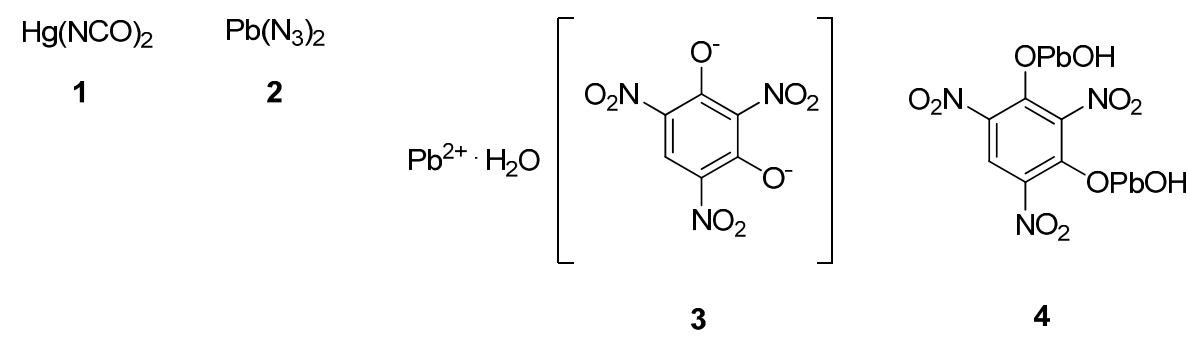

Figure 1. Chemical structure of the primary explosives; mercury fulminate (1), lead azide (2) and normal lead styphnate (3) and basic lead styphnate (4).

\subsection{Why "Green" Primary Explosives?}

Over the past two decades, there has been a significant interest amongst the US Department of Defense (DoD) community, in particular, to address environmental issues associated with military explosives, propellants, and pyrotechnics. Today, lead azide and lead styphnate comprise the vast majority of military and civilian primary explosive use. The obvious issue with these two materials is the presence of lead, which is an established heavy metal toxin. Until the 1960s, these materials were not believed to significantly impact health [10]. Over the past five decades, however, the view of lead-based primary explosives has changed significantly. Ingestion and/or inhalation of lead is now known to affect the central nervous system, the renal system, the blood, and has been a contributing factor in mental impairment and behavioral issues [11]. Lead has become one of the most regulated chemical substances on an international scale. It is classified as a toxic pollutant in the USA, and efforts have been underway for decades to remove lead from Federal facilities, including DoD facilities [12]. In 2012, the National Research Council recommended that the DoD review its 30 years old policy on protecting workers from lead exposure in firing ranges [13]. In Europe, the Registration, Evaluation, Authorization, and Restriction of Chemicals (REACH) program has called for the specific regulation of lead azide and lead styphnate. Therefore, a clear need exists for the successful development and replacement of these two aforementioned primary explosives.

Aside from the environmental concerns associated with lead azide, a further complication exists in that the material is known to slowly decompose under ambient conditions (Scheme 1). Lead azide reacts with $\mathrm{CO}_{2}$ and $\mathrm{H}_{2} \mathrm{O}$ to produce basic lead carbonate and highly toxic hydrazoic acid $\left(\mathrm{HN}_{3}\right)$. $\mathrm{HN}_{3}$ can react with exposed copper metal surface in pipes and wires, thus generating the highly sensitive and deadly copper azide $\left(\mathrm{Cu}\left(\mathrm{N}_{3}\right)_{2}\right)$. Several fatal military accidents over the years have been associated with the accidental generation of copper azide [14].

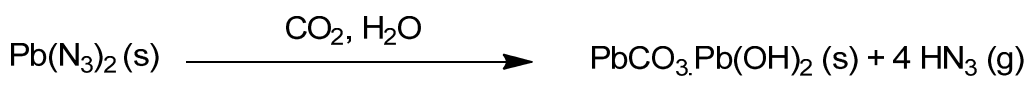

Scheme 1. Decomposition reaction of lead azide.

\section{3. "Green" Primary Explosive Candidates}

\subsubsection{Metal-Free Primary Explosives}

\subsubsection{Cyanuric Triazide (CTA)}

CTA (6), prepared in a single, efficient, and eco-friendly step by treatment of cyanuric trichloride (5) with sodium azide (Scheme 2), has more explosive power than lead azide, making it a suitable replacement for lead azide in large-sized detonators. Unfortunately, there are several complications with the material, in particular its tendency to undergo sublimation at elevated temperatures [15]. Further, the earlier syntheses of CTA reported an extreme sensitivity of the material to ignition 
stimuli [16]. The crystalline material from the earlier syntheses exhibited a needle-like morphology, which broke easily, thus increasing the risk of accidental detonation.<smiles>CC(C)(C)O[N+](=O)CO</smiles>

Scheme 2. Synthesis of cyanuric triazide (CTA, 6).

Although CTA was first patented in 1921 [17], a newer synthetic procedure for the material developed by ARDEC in 2009 resulted in a reduced particle size of the material [18]. As a result of the new synthesis procedure, CTA has been further investigated by researchers at ARDEC, and has found successful use as a replacement for both lead azide and lead styphnate in the NOL-130 stab detonator mix, as well as some more recent work as a potential lead styphnate replacement in percussion primer formulations (NB: The lead-based NOL-130 formulation consists of $40 \%$ lead styphnate, $20 \%$ lead azide, $20 \%$ barium nitrate, $15 \%$ antimony trisulfide, and $5 \%$ tetrazene). The sublimation of CTA, and thus its looming safety issues, however, remains an Achilles heel for this material if it is to ever gain serious traction in having widespread serious military and civilian applications.

\subsubsection{2-Diazo-4,6-Dinitrophenol (DDNP)}

The synthesis of DDNP (9) is described in Scheme 3. Treatment of picric acid (7) with a controlled simultaneous addition of aqueous sodium sulfide yields sodium picramate (8), which is then converted to DDNP via the Griess diazotization. DDNP has found explosive use since the early 20th century [1]. Although old enough to be considered a legacy primary explosive, it tends to fall into a different category because of its heavy metal-free nature.<smiles>N#[N+]c1cc([N+](=O)[O-])c(O)c([N+](=O)[O-])c1</smiles>

Scheme 3. Synthesis of DDNP (9).

At this time, DDNP is generally considered to be an unsuitable candidate for demanding military primer applications. The material is reputed to suffer from reliability issues in extreme cold weather climates. DDNP's low sensitivity to friction, its low flame temperature, and its incompatibility with lead azide also plague this compound [19]. Due to different requirements necessary for the production of commercial primer formulations, DDNP has found recent usage and interest from the civilian sectors as a "green" replacement for lead styphnate in primer applications [20,21].

\subsubsection{Peroxide-Based Explosives}

Although primary explosives are designed with the intent to be sensitive to various ignition stimuli, it has always been believed that peroxide-based explosives are too sensitive to garner practical use for even primary explosive applications. Chemically, the high degree of instability of the oxygen-oxygen bond is the culprit behind this sensitivity. Two peroxide-based materials that have been studied extensively are triacetone triperoxide (TATP) and hexamethylenetriperoxide diamine (HMTD). Their syntheses are remarkably simple and are performed from cheap, commercially 
available starting materials, as summarized in Scheme 4. TATP (10) and HMTD (11) are synthesized from acetone and hexamine, respectively, in the presence of acidic water and hydrogen peroxide. The historically negative safety profile of peroxide-based primary explosives, coupled with the blatant terroristic use of materials such as TATP and HMTD have discouraged the investigation and use of organic peroxides as a viable energetic material for practical use.
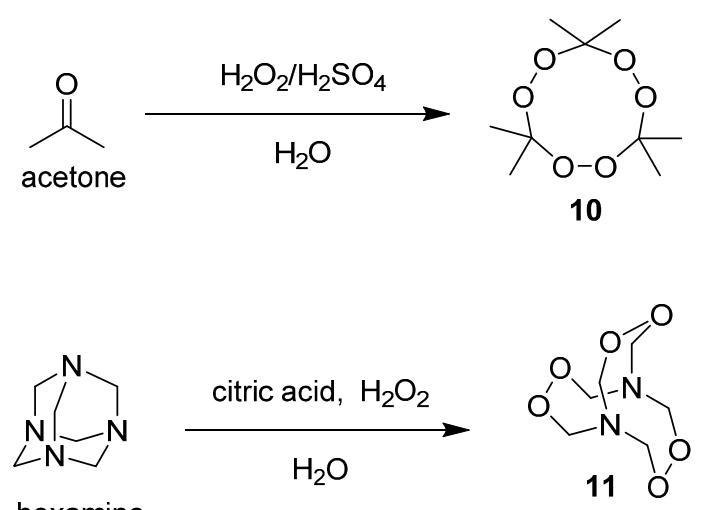

Scheme 4. Synthesis of TATP (10) and HMTD (11).

Work spearheaded by Winter in 2015, however, has shown that organic peroxides can be designed that exhibit high performance, yet reasonable sensitivities [22]. As summarized in Scheme 5, a given diketone or dialdehyde was reacted with hydrogen peroxide in the presence of a catalytic amount of iodine to afford the bis-geminal hydroperoxy derivatives $12-15$. Despite the presence of normally labile peroxy groups, it is believed that the lability is suppressed due to the presence of intermolecular $\mathrm{O}-\mathrm{H}$... O hydrogen bonds, as well as several $\mathrm{O} \ldots \mathrm{O}$ and $\mathrm{C} \ldots \mathrm{H}$ close contacts which was determined to occur in the crystalline lattice of 15 upon confirmation of the structure by single crystal X-ray diffraction.
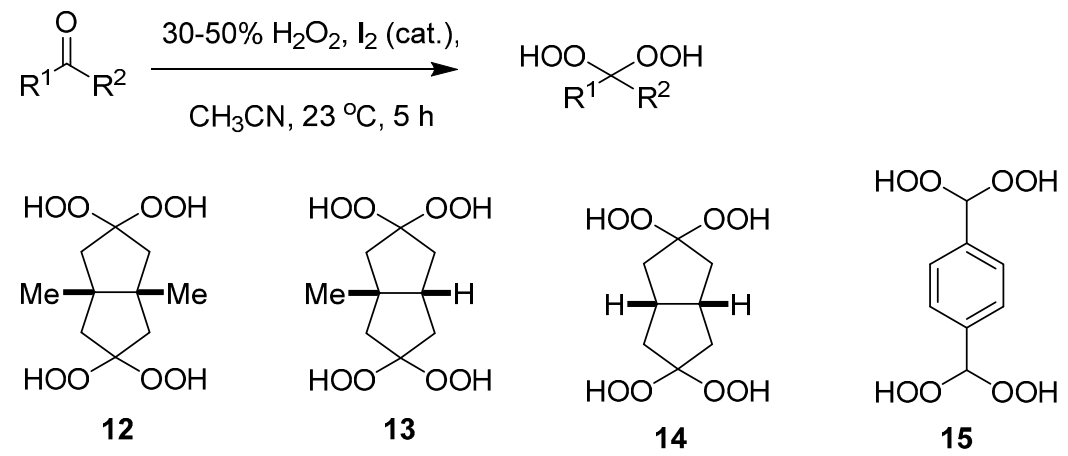

Scheme 5. Synthesis of stable peroxide-based primary explosives.

The sensitivities and performance of geminal peroxides 12-15, compared to TATP, are summarized in Table 1. Remarkably, geminal peroxy compounds $12-15$ are more insensitive to impact and friction than TATP, with comparable or better ESD sensitivities. This phenomenon occurs despite the better oxygen balances, higher crystalline densities, higher detonation velocities, and total energy of detonation values compared to TATP. The Winter approach is unique because it describes the first known examples of stabilized peroxide-based primary explosives. Although the thermal stabilities of this class of compounds could use some improvement, the area of peroxide-based primary explosives, in light of this discovery, ought to be investigated further for possible application. 
Table 1. Sensitivities and performance of geminal peroxides 12-15 and TATP.

\begin{tabular}{|c|c|c|c|c|c|}
\hline Data Category & 12 & 13 & 14 & 15 & TATP \\
\hline IS [J] ${ }^{a}$ & 2 & 1 & 2 & 3 & 0.3 \\
\hline $\mathrm{FS}[\mathrm{N}]^{\mathrm{b}}$ & 5 & 5 & 5 & $<5$ & 0.1 \\
\hline $\operatorname{ESD}^{\mathrm{c}}[\mathrm{J}]^{\mathrm{c}}$ & 0.2 & 0.5 & 0.1 & 0.25 & 0.16 \\
\hline$T_{\mathrm{dec}}\left[{ }^{\circ} \mathrm{C}\right]^{\mathrm{d}}$ & 117 & 98 & 100 & 105 & $150-160$ \\
\hline$\Omega_{\mathrm{CO}_{2}}[\%]^{\mathrm{e}}$ & -126.2 & -114.18 & -100.76 & -88.83 & -151.19 \\
\hline$\rho[\mathrm{g} / \mathrm{cc}]^{\mathrm{f}}$ & 1.35 & 1.375 & 1.6 & 1.6 & 1.18 \\
\hline$P_{\mathrm{cj}}[\mathrm{kbar}]^{\mathrm{g}}$ & 117 & 126 & 195 & 195 & - \\
\hline$V_{\operatorname{det}}[\mathrm{m} / \mathrm{s}]^{\mathrm{h}}$ & 6150 & 6250 & 6428 & 7130 & 5300 \\
\hline$\Delta_{\mathrm{f}} H^{0}[\mathrm{~kJ} / \mathrm{mol}]^{\mathrm{i}}$ & -703.6 & -660.8 & -418.2 & -418.2 & -583.8 \\
\hline$\Delta_{\mathrm{ex}} U^{0}[\mathrm{~kJ} / \mathrm{kg}]^{\mathrm{j}}$ & -4636 & -4875 & -5083 & -5498 & -2745 \\
\hline
\end{tabular}

${ }^{a}$ IS = impact sensitivity; ${ }^{\mathrm{b}} \mathrm{FS}=$ friction sensitivity; ${ }^{\mathrm{c}} \mathrm{ESD}=$ electrostatic discharge; ${ }^{\mathrm{d}} T_{\mathrm{dec}}=$ Temperature of decomposition; ${ }^{\mathrm{e}} \Omega_{\mathrm{CO}_{2}}=\mathrm{CO}_{2}$ oxygen balance; ${ }^{\mathrm{f}} \rho=$ crystalline density; ${ }^{\mathrm{g}} P_{\mathrm{cj}}=$ detonation pressure;

${ }^{\mathrm{h}} V_{\text {det }}=$ detonation velocity; ${ }^{\mathrm{i}} \Delta_{\mathrm{f}} H^{0}=$ molar enthalpy of formation; ${ }^{j} \Delta_{\mathrm{ex}} U^{0}=$ total energy of detonation.

\subsubsection{Tetrazene and MTX-1}

1-Amino-1-(1H-tetrazol-5-yl)-azo-guanidine hydrate, known colloquially as tetrazene (16), is a well-known sensitizer in percussion primer compositions (Figure 2) [8]. Without its presence in primers, initiation is known to be dreadfully unreliable, or fails to function altogether. Despite its reliability and widespread use in primers, tetrazene suffers from a high degree of hydrolytic and thermal instability. It has been found to rapidly decompose at temperatures of $c a .90{ }^{\circ} \mathrm{C}$, and this temperature is commonly encountered during handling and storage of the material. Addition of boiling water to tetrazene is also known to rapidly decompose the material.<smiles>N=C(N)N(N)/N=N/c1nn[nH]n1</smiles>

16<smiles>NC(N)=NN=Nc1nn[nH]n1</smiles>

17

Figure 2. Molecular structure of tetrazene (16) and MTX-1 (17).

In light of these concerns, Fronabarger and Williams reacted tetrazene in aqueous solution to produce MTX-1, which has promise for serving as a more thermally stable replacement $[23,24]$. Initial studies have shown that while tetrazene decomposes exothermically at $144^{\circ} \mathrm{C}, \mathrm{MTX}-1$ undergoes exothermic decomposition at $214{ }^{\circ} \mathrm{C}$. Holding tetrazene at $90{ }^{\circ} \mathrm{C}$ for $120 \mathrm{~h}$ results in $36 \%$ weight loss, while MTX-1 experiences just $4 \%$ weight loss after the same time periods. Exposure of MTX- 1 to water for 120 days has virtually no effect, as MTX-1 can be re-isolated in nearly quantitative yield. It has been stated that MTX-1 has comparable impact, friction and ESD sensitivities to tetrazene, thus adding to its appeal as a potential replacement to this traditionally used organic sensitizing agent in primer compositions.

\subsubsection{Metal-Organic Primary Explosives}

\subsubsection{Potassium 4,6-Dinitrobenzofuroxan (KDNBF)}

KDNBF (21) is synthesized in a three-step procedure, as summarized in Scheme 6 [25]. Exposure of $o$-nitroaniline to $\mathrm{NaOCl}$ and base affords benzofuroxan 19, which is subjected to mixed acid nitration to yield dinitrobenzofuroxan 20. Treatment of dinitrobenzofuroxan with potassium bicarbonate furnishes KDNBF. 


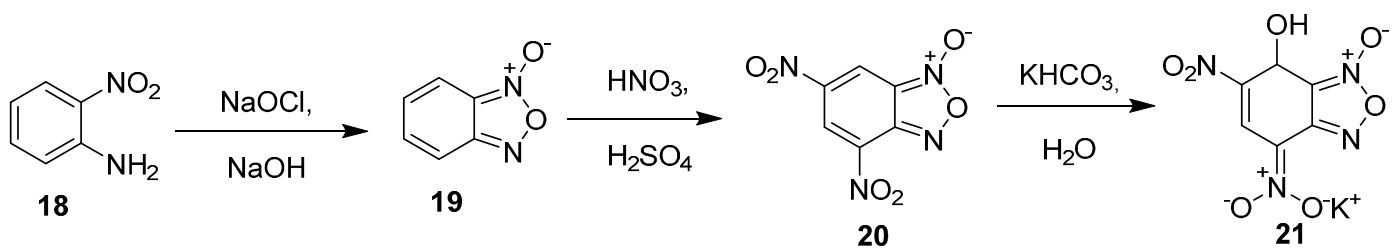

Scheme 6. Synthesis of KDNBF.

Potassium is generally considered an innocuous and much safer alternative to lead. Thus, KDNBF, much like DDNP, has found use as a suitable "green" primary explosive alternative to lead styphnate in civilian primer compositions. While lead styphnate has a decomposition temperature of $280-290^{\circ} \mathrm{C}$, KDNBF's decomposition temperature is much lower $\left(217^{\circ} \mathrm{C}\right)$. Also like DDNP, $\mathrm{KDNBF}$ has not been adopted for widespread military use; the lower thermal stability of KDNBF may be one of the reasons as to why this material has not been used as a universal alternative to lead styphnate in primary explosive compositions.

\subsubsection{Potassium 4,6-Dinitro-7-Hydroxybenzofuroxan (KDNP)}

Scheme 7 details the synthesis of KDNP (25) [26]. Mixed acid nitration of 3-bromoanisole delivered trinitro derivative 23 . This material was treated with potassium azide in refluxing methanol to effect concomitant substitution at C-3 and cleavage of the methyl ether, thus yielding azide 24. Treatment of this azide with diethylcarbonate in heat produces KDNP (25). The approach detailed in Scheme 6 is an improvement over previous syntheses that required the use of water, which was retained in the product. This led to the formation of needles that were capable of breaking, and thus dramatically increased the sensitivity of the material. The new synthetic procedure allowed for a free-flowing powder to be obtained, and particle size could be varied by simple variations in temperature and the addition rate of the solvent during recrystallization.

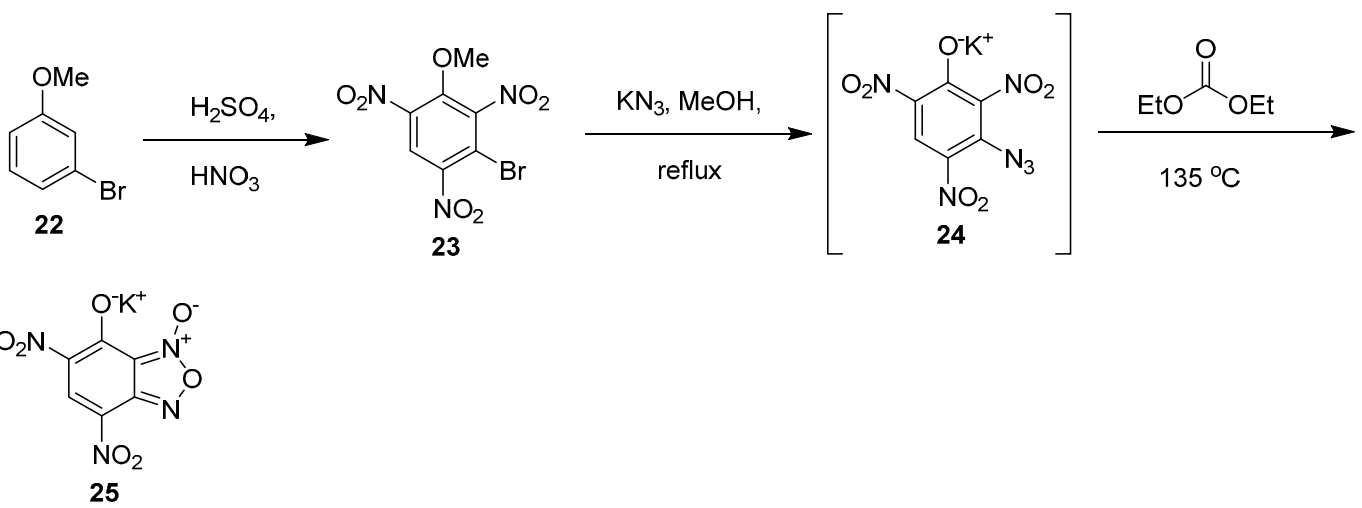

Scheme 7. Synthesis of KDNP (25).

Though originally synthesized over 30 years ago, KDNP has drawn renewed interest as a lead styphnate replacement, due to its comparable explosive performance in military-relevant primers and its thermal stability, as provided in Table $2[22,26]$. Note the structural similarities that exist between KDNBF and KDNP; though KDNP possess a single hydrogen atom less than KDNBF, the absence of this hydrogen allows for the restoration of aromaticity in the benzofuroxan ring system. This phenomenon likely serves to explain the increased thermal stability of KDNP compared to KDNBF. 
Table 2. Sensitivities and performance of KDNP (25).

\begin{tabular}{cc}
\hline Data Category & KDNP (25) \\
\hline IS [J] ${ }^{\mathrm{a}}$ & 0.047 \\
$\mathrm{FS}[\mathrm{N}]^{\mathrm{b}}$ & 9.81 \\
$\mathrm{ESD}^{\mathrm{c}}[\mu \mathrm{\mu J}]^{\mathrm{c}}$ & $>675$ \\
$T_{\mathrm{dec}}\left[{ }^{\circ} \mathrm{C}\right]^{\mathrm{d}}$ & 285 \\
$\Omega_{\mathrm{CO}_{2}[\%]^{\mathrm{e}}}$ & -34.3 \\
$\left.\rho^{\mathrm{e}} / \mathrm{g} / \mathrm{cc}\right]^{\mathrm{f}}$ & 1.982 \\
$\Delta_{\mathrm{f}} H^{0}[\mathrm{~kJ} / \mathrm{mol}]^{\mathrm{g}}$ & -197.07 \\
$\Delta_{\mathrm{ex}} U^{0}[\mathrm{~kJ} / \mathrm{kg}]^{\mathrm{h}}$ & 3280
\end{tabular}

a IS = impact sensitivity; ${ }^{\mathrm{b}} \mathrm{FS}=$ friction sensitivity; ${ }^{\mathrm{c}} \mathrm{ESD}=$ electrostatic discharge; ${ }^{\mathrm{d}} T_{\mathrm{dec}}=$ Temperature of decomposition; ${ }^{\mathrm{e}} \Omega_{\mathrm{CO}_{2}}=\mathrm{CO}_{2}$ oxygen balance; ${ }^{\mathrm{f}} \rho=$ crystalline density; ${ }^{\mathrm{g}} \Delta_{\mathrm{f}} H^{0}=$ molar enthalpy of formation; ${ }^{\mathrm{h}} \Delta_{\mathrm{ex}} U^{0}=$ total energy of detonation.

\subsubsection{Potassium 1,1'-dinitramino-5,5'-Bis(tetrazolate) ( $\left.\mathrm{K}_{2} \mathrm{DNABT}\right)$}

In 2014, Klapötke reported the synthesis and performance of $K_{2}$ DNABT (31) [27]. This material is prepared in a seven step sequence, starting from dimethyl carbonate (Scheme 8). Desymmetrization of dimethyl carbonate, followed by condensation with glyoxal afforded bis(hydrazone) 27. Treatment with $\mathrm{N}$-chlorosuccinimide (NCS), followed by displacement of the chlorines with azide, afforded diazido bis(hydrazone) intermediate (29). Acid-induced cyclization to give bis(tetrazole) (30), nitration of this species with dinitrogen pentoxide, and formation of the resultant dipotassium salt afforded $\mathrm{K}_{2}$ DNABT.

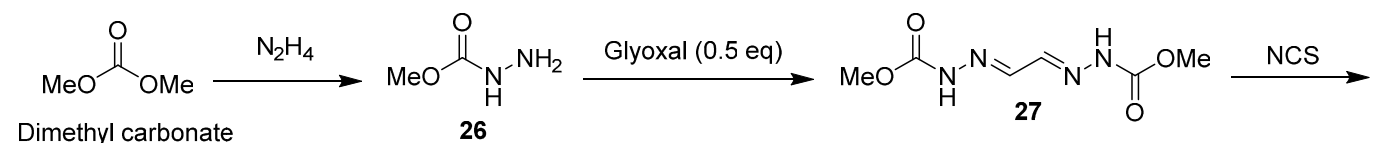
Dimethyl carbonate 26

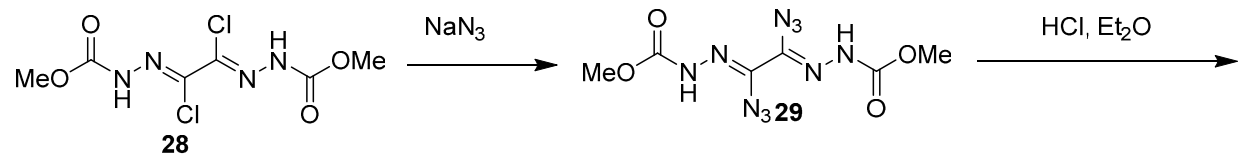

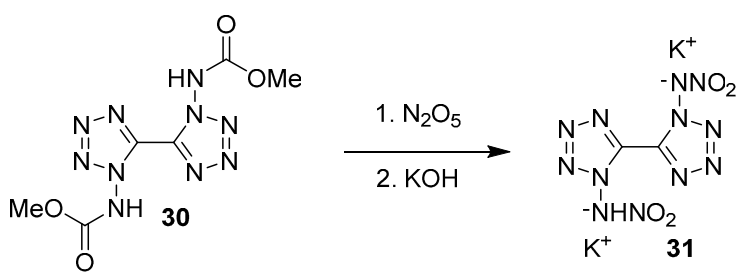

Scheme 8. Synthesis of $\mathrm{K}_{2}$ DNABT (31).

$\mathrm{K}_{2} \mathrm{DNABT}$ was prepared based on the premise that it could serve as a potential replacement for lead azide in detonator applications; it is particularly intriguing in that it incorporates two 1-nitraminotetrazole moieties, each consisting of six consecutive nitrogen atoms which contribute greatly to the high explosive output of the molecule. Compared to lead azide, $\mathrm{K}_{2} \mathrm{DNABT}$ was found to have comparable sensitivities to impact, friction and ESD, a significantly larger detonation velocity, and a similar detonation pressure (Table 3). $\mathrm{K}_{2}$ DNABT was subjected to $100^{\circ} \mathrm{C}$ for $48 \mathrm{~h}$ and was found to undergo no mass loss or decomposition at this temperature. Undoubtedly, this material holds promise and should be investigated further as a potential alternative to lead azide. However, its current synthesis does suffer from a lengthy synthesis route, and low yields were encountered in some of the synthetic transformations; most notably, the conversion of dichloro bis(hydrazone) (28) to diazido bis(hydrazone) (29), which proceeded in only $38 \%$ yield. 
Table 3. Sensitivities and performance of $\mathrm{K}_{2} \mathrm{DNABT}$ as compared to $\mathrm{Pb}\left(\mathrm{N}_{3}\right)_{2}$.

\begin{tabular}{ccc}
\hline Data Category & $\mathbf{K}_{\mathbf{2}}$ DNABT (31) & $\mathbf{P b}\left(\mathbf{N}_{\mathbf{3}} \mathbf{~} \mathbf{2}_{\mathbf{2}}\right.$ \\
\hline IS [J] ${ }^{\mathrm{a}}$ & 1 & $2.5-4$ \\
$\mathrm{FS}[\mathrm{N}]^{\mathrm{b}}$ & $\leqslant 1$ & $0.1-1$ \\
$\mathrm{ESD}^{\mathrm{c}}[\mathrm{J}]^{\mathrm{c}}$ & 0.003 & $<0.005$ \\
$T_{\mathrm{dec}}\left[{ }^{\circ} \mathrm{C}\right]^{\mathrm{d}}$ & 200 & 315 \\
$\Omega_{\mathrm{CO}_{2}}[\%]^{\mathrm{e}}$ & -4.8 & -11 \\
$\rho_{\mathrm{g} / \mathrm{cc}]^{\mathrm{f}}}^{\mathrm{f}}$ & 2.11 & 4.8 \\
$P_{\mathrm{cj}}[\mathrm{kbar}]^{\mathrm{g}}$ & 5920 & 8330 \\
$V_{\mathrm{det}}[\mathrm{m} / \mathrm{s}]^{\mathrm{h}}$ & 33.8 & 31.7 \\
$\Delta_{\mathrm{f}} H^{0}[\mathrm{~kJ} / \mathrm{mol}]^{\mathrm{i}}$ & 326.4 & 450.1 \\
$\Delta_{\mathrm{ex}} U^{0}[\mathrm{~kJ} / \mathrm{kg}]^{\mathrm{j}}$ & 1036.1 & 1569
\end{tabular}

${ }^{\mathrm{a}}$ IS = impact sensitivity; ${ }^{\mathrm{b}} \mathrm{FS}=$ friction sensitivity; ${ }^{\mathrm{c}} \mathrm{ESD}=$ electrostatic discharge; ${ }^{\mathrm{d}} T_{\mathrm{dec}}=$ Temperature of decomposition; ${ }^{\mathrm{e}} \Omega_{\mathrm{CO}_{2}}=\mathrm{CO}_{2}$ oxygen balance; ${ }^{\mathrm{f}} \rho=$ crystalline density; ${ }^{\mathrm{g}} P_{\mathrm{cj}}=$ detonation pressure;

${ }^{\mathrm{h}} V_{\text {det }}=$ detonation velocity; ${ }^{\mathrm{i}} \Delta_{\mathrm{f}} H^{0}=$ molar enthalpy of formation; ${ }^{j} \Delta_{\mathrm{ex}} U^{0}=$ total energy of detonation.

\subsubsection{1,5-(dinitramino) Tetrazole Dipotassium Salt}

In 2015, Klapötke went on to synthesize the similarly structured dipotassium salt of 1,5-dinitramino tetrazole (33), as described in Scheme 9 [24,28]. Treatment of methyl carbazate 26 with cyanogen azide produced tetrazole (32), which was subjected to nitration, followed by basic conditions to give the dipotassium salt of 1,5-Dinitramino tetrazole.

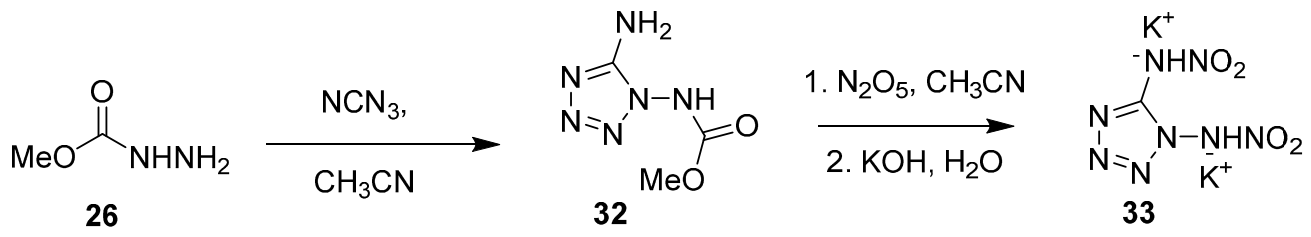

Scheme 9. Synthesis of the dipotassium salt of 1,5-Dinitramino tetrazole (33).

Tetrazene and its organic-based replacement, MTX-1, was discussed in Section 2.3.1. Klapötke has reasoned that given the high density, detonation velocity, detonation pressure, and impact and friction sensitivity of (33) (Table 4), this compound could also serve as a potential replacement for tetrazene as a sensitizing agent in primary explosive formulations. The shockwave produced by $50 \mathrm{mg}$ of (33) was found to easily detonate the secondary explosive RDX.

Table 4. Sensitivities and performance of the dipotassium salt of 1,5-Dinitramino tetrazole (33) and CL-20.

\begin{tabular}{|c|c|c|}
\hline Data Category & 33 & CL-20 \\
\hline IS [J] ${ }^{a}$ & 1 & 4 \\
\hline $\mathrm{FS}[\mathrm{N}]^{\mathrm{b}}$ & $\leqslant 5$ & 48 \\
\hline$T_{\mathrm{dec}}\left[{ }^{\circ} \mathrm{C}\right]^{\mathrm{c}}$ & 240 & 315 \\
\hline$\Omega_{\mathrm{CO}_{2}}[\%]^{\mathrm{d}}$ & -12.03 & -10.95 \\
\hline$\rho[\mathrm{g} / \mathrm{cc}]^{\mathrm{e}}$ & 2.177 & 2.04 \\
\hline$P_{\mathrm{cj}}[\mathrm{kbar}]^{\mathrm{f}}$ & 522 & 444 \\
\hline$V_{\text {det }}[\mathrm{m} / \mathrm{s}]^{\mathrm{g}}$ & 10011 & 9730 \\
\hline$\Delta_{\mathrm{f}} H^{0}[\mathrm{~kJ} / \mathrm{mol}]^{\mathrm{h}}$ & -112.4 & 365.4 \\
\hline$\Delta_{\mathrm{ex}} U^{0}[\mathrm{~kJ} / \mathrm{kg}]^{\mathrm{i}}$ & 3938 & 6168 \\
\hline
\end{tabular}

a IS = impact sensitivity; ${ }^{\mathrm{b}}$ FS = friction sensitivity; ${ }^{\mathrm{c}} T_{\mathrm{dec}}=$ Temperature of decomposition;

${ }^{\mathrm{d}} \Omega_{\mathrm{CO}_{2}}=\mathrm{CO}_{2}$ oxygen balance; ${ }^{\mathrm{e}} \rho=$ crystalline density; ${ }^{\mathrm{f}} P_{\mathrm{cj}}=$ detonation pressure; ${ }^{\mathrm{g}} V_{\text {det }}=$ detonation velocity;

${ }^{\mathrm{h}} \Delta_{\mathrm{f}} H^{0}=$ molar enthalpy of formation; ${ }^{\mathrm{i}} \Delta_{\mathrm{ex}} U^{0}=$ total energy of detonation. 


\subsubsection{Copper(I) 5-Nitrotetrazolate (DBX-1)}

DBX-1 has been a compound of intense investigation recently, due to its similarities to lead azide with respect to its initiating ability and impact, friction and ESD sensitivity, as well as high thermal stability [29]. Unlike the blue copper(II) nitrotetrazole octahedral complex reported by Huynh [30], DBX-1 is the copper(I) salt that manifests as orange-red crystals and adopts the dimeric structure (as determined by single-crystal X-ray) shown in Scheme 10. More importantly, it can easily be synthesized as a free-flowing powder (essential for practical applications) which was never observed for the Huynh compounds. Further, DBX-1 has been successfully demonstrated to be a "drop-in" replacement for lead azide (meaning it can be substituted as a direct, volume-for-volume replacement with no hardware changes) in some existing detonator designs. It is also being investigated as a replacement for lead styphnate in certain applications as well. DBX-1 has been shown to be more resistant to oxidation than lead azide when subjected to thermal cycling conditions (i.e., high temperature and high humidity). DBX-1 is known to slowly decompose when stored in water, and shows incompatibility when in the presence of periodate-based oxidizers [31]. Nonetheless, due to the aforementioned positive qualities, DBX-1 is being sought as a replacement for lead-based primary explosives.

The traditional synthetic procedure for making DBX-1 is described in Scheme 10. Exposure of 5-aminotetrazole to a modified Sandmeyer reaction affords copper acid salt 34, which is converted to the sodium salt of 5-nitrotetrazole (NaNT, 35) upon exposure to $\mathrm{NaOH}$ as originally described by von Herz [32] and later modified by Gilligan [33]. Subsequently, $\mathrm{CuCl}_{2}$ is treated with sodium ascorbate to generate the copper(I) species in situ, which reacts with NaNT to yield DBX-1 (36). The performance and sensitivities for this compound are detailed in Table 5.

Table 5. Performance and sensitivities of DBX-1 (36).

\begin{tabular}{cc}
\hline Data Category & DBX-1 (36) \\
\hline IS $[\mathrm{J}]^{\mathrm{a}}$ & 0.036 \\
$\mathrm{FS}[\mathrm{N}]^{\mathrm{b}}$ & $>0.098$ \\
$\mathrm{ESD}^{\mathrm{c}}[\mu \mathrm{J}]^{\mathrm{c}}$ & 12 \\
$T_{\mathrm{dec}}\left[{ }^{\circ} \mathrm{C}\right]^{\mathrm{d}}$ & 337 \\
$\Omega_{\mathrm{CO}_{2}[\%]^{\mathrm{e}}}$ & -9.0 \\
$\rho^{\mathrm{g} / \mathrm{cc}]^{\mathrm{f}}}$ & 2.584 \\
$\Delta_{\mathrm{f}} H^{0}[\mathrm{~kJ} / \mathrm{mol}]^{\mathrm{g}}$ & 280.9 \\
$\Delta_{\mathrm{ex}} U^{0}[\mathrm{~kJ} / \mathrm{kg}]^{\mathrm{h}}$ & 3816.6
\end{tabular}

a IS = impact sensitivity; ${ }^{\mathrm{b}} \overline{\mathrm{FS}}=$ friction sensitivity; ${ }^{\mathrm{c}} \mathrm{ESD}=$ electrostatic discharge $;{ }^{\mathrm{d}} T_{\mathrm{dec}}=$ Temperature of decomposition; ${ }^{\mathrm{e}} \Omega_{\mathrm{CO}_{2}}=\mathrm{CO}_{2}$ oxygen balance; ${ }^{\mathrm{f}} \rho=$ crystalline density; ${ }^{\mathrm{g}} \Delta_{\mathrm{f}} H^{0}=$ molar enthalpy of formation; ${ }^{\mathrm{h}} \Delta_{\mathrm{ex}} U^{0}=$ total energy of detonation.

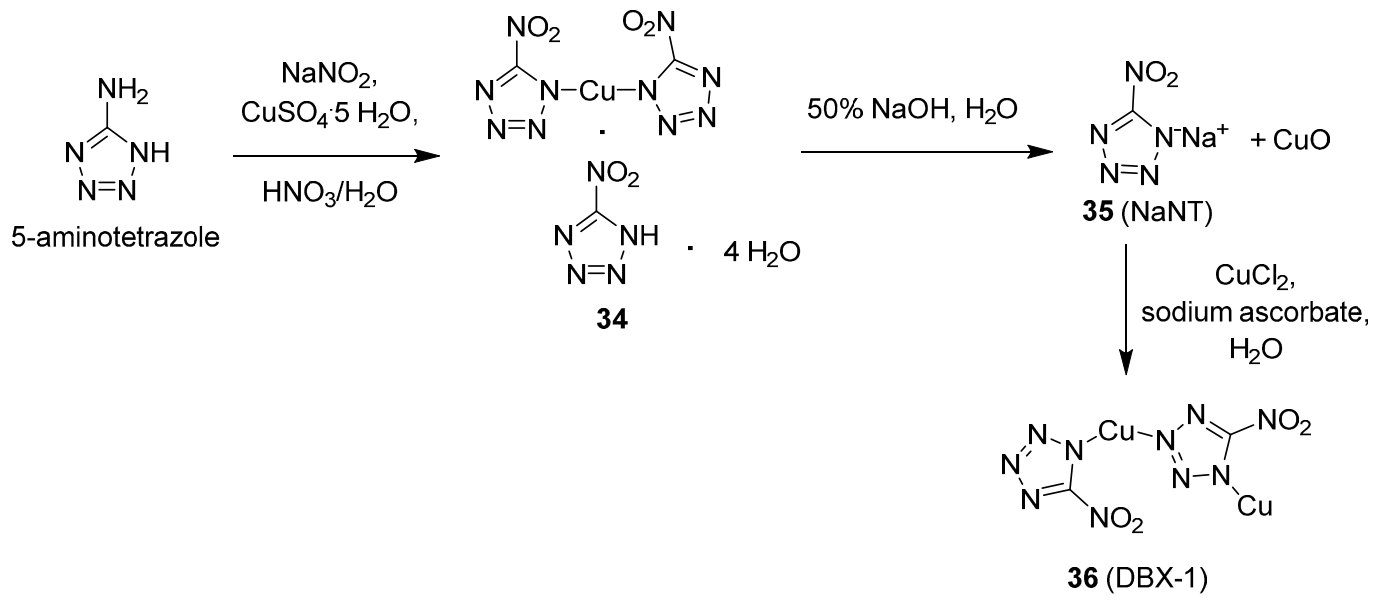

Scheme 10. Traditional synthetic pathway of DBX-1. 
There are several concerns with this traditional synthesis as described. Since this route has been discovered, microdetonations have been reported during the reaction; a presumed result of generating the highly dangerous 5-diazotetrazole in the modified Sandmeyer reaction. On a laboratory-scale, some improvements have been made over time including the addition of a copper(II) species such as $\mathrm{CuSO}_{4} \cdot 5 \mathrm{H}_{2} \mathrm{O}$ to suppress the microdetonation events by converting 5 -diazotetrazole to the innocuous 5-hydroxytetrazole. Furthermore, employing an excess of sodium nitrite in the reaction mixture enhances the safety of the filtration step to isolate copper acid salt (34). Unfortunately, the microdetonation and dangerous filtration of copper acid salt (34) commonly resurface when NaNT is synthesized on a production-sized scale. Therefore, the inability to manufacture NaNT, and thus, DBX-1 on a production-sized scale has been a major drawback that has limited practical application for the material.

Fortunately, pioneering work at Nalas Engineering by Salan and co-workers have solved this looming issue [34]. Throughout the course of their investigation, it was discovered that synthesizing NaNT by the traditional method shown in Scheme 10 does not result in a pure product. NaNT is obtained through this method with ca. 5\% 5-aminotetrazole as an impurity. Furthermore, in synthesizing copper acid salt (34), it was discovered that use of $\mathrm{HNO}_{3}$ in the modified Sandmeyer protocol led to the depositing of the explosive 5-aminotetrazole nitrate on the feeding lines.

To mitigate these issues, $\mathrm{HNO}_{3}$ was replaced with $\mathrm{H}_{2} \mathrm{SO}_{4}$ in the modified Sandmeyer reaction (Scheme 11).
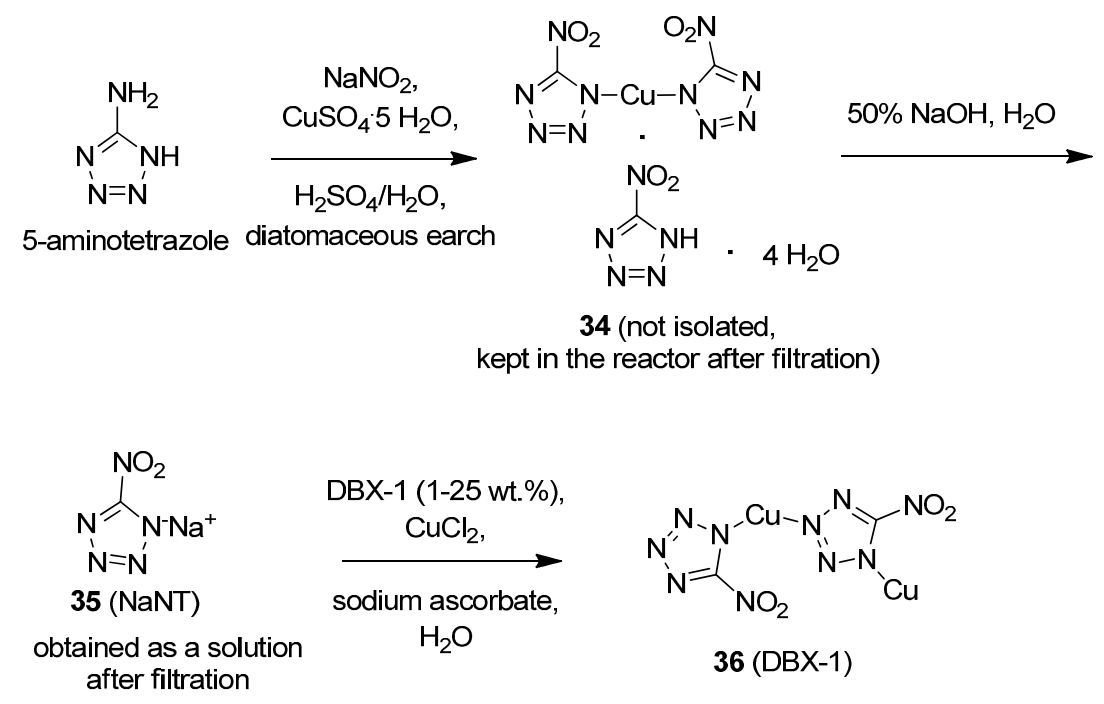

Scheme 11. Improved synthesis of DBX-1 as performed by Nalas Engineering.

In addition to eliminating the possibility of forming 5-aminotetrazole nitrate, 5-aminotetrazole was found to be at least twice as soluble in sulfuric acid as in nitric acid. The addition of diatomaceous earth to the reaction mixture during the modified Sandmeyer protocol resulted in copper acid salt (34) being retained in the solid phase during washing/purification. Treatment of diatomaceous earth/copper acid salt 34 with $\mathrm{NaOH}$ resulted in the formation of NaNT, which could be isolated in relatively pure solution by keeping the mother liquor following filtration. In converting NaNT solution to DBX-1, it was found that doping the reaction mixture with 1-25 wt \% of authentic DBX-1 was extremely beneficial in minimizing the induction period of forming DBX-1, and led to an increased likelihood that a batch of NaNT would be converted to DBX-1. Throughout the process, handling of any sensitive intermediates in making DBX-1 is avoided, thus increasing the safety of the operators involved. In light of these significant improvements, it appears that DBX-1 will garner enthusiastic interest as a lead-free primary explosive in detonator and primer applications. 


\section{Secondary Explosives}

\subsection{Legacy Secondary Explosives and Why Interest Exists in Developing Alternatives}

Unlike primary explosives, secondary explosives are usually harder to initiate, but typically have higher performance, such as higher detonation velocities and detonation pressures. Figure 3 depicts some examples of legacy secondary explosives that have been adopted for use (in some cases, widespread use) for military and/or civilian applications. CL-20 (2,4,6,8,10,12-hexanitro-2,4,6,8,10,12-hexaazaisowurtzitane, 40) has a particularly high performance, but it has failed to find many applications in explosive formulations due to the costs associated in making this material, which involves palladium catalysis. There has been interest from the environmental community to discovery metal-free syntheses of CL-20 [35], but no successful alternative has been demonstrated to date.

2,4,6-Trinitrotoluene (TNT, 37) is the most commonly known secondary explosive in existence today amongst the general public, and its use has historically been prevalent in military and civilian sectors. It has found widespread use in the USA since World War I, and is a common ingredient in explosive mortar and artillery shells, and bombs, for example. The melting point of TNT $\left(80^{\circ} \mathrm{C}\right)$ is significantly below its explosive decomposition temperature, which makes the material useful as a melt-castable explosive. The insensitive nature of TNT is beneficial because it minimizes the risk of accidental detonation. Unfortunately, TNT has a negative toxicity profile by today's increasingly stringent environmental and human health safety standards. Pink and red wastewater-the former produced during the washing of equipment following munitions filling, and the latter produced during the purification process of the crude material—are associated with TNT. Long-term exposure to TNT has been linked to adverse health effects, and so a replacement for TNT has been sought, particularly amongst the insensitive munitions community.<smiles>Cc1c([N+](=O)[O-])cc([N+](=O)[O-])cc1[N+](=O)[O-]</smiles>

37<smiles>O=[N+]([O-])[N+](=O)[N+](=O)[O-]</smiles>

38<smiles>O=[N+]([O-])[N+](=O)[O-]</smiles>

39

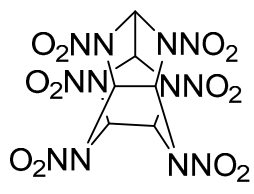

40

Figure 3. Examples of legacy secondary explosives TNT (37), RDX (38), HMX (39), and CL-20 (40).

Royal Demolition Explosive (RDX, 1,3,5-trinitro-1,3,5-triazacyclohexane, 38), which is inexpensively prepared from hexamine, is produced efficiently by a method known as the Bachmann process. This process also produces HMX (1,3,5,7-tetranitro-1,3,5,7-tetraazacyclooctane, 39) as a by-product [36]. RDX is manufactured on massive scale, and has been used commonly since World War II. RDX is significantly higher in explosive performance than TNT. The material is rather insensitive at room temperature, and is often the "gold standard" used when determining acceptable sensitivities when new secondary explosives are being designed. Like TNT, RDX has come under increasing pressure from the EPA for regulation due to concerns that the molecule does not bind to soil effectively, and thus may contaminate groundwater supplies. The EPA has classified RDX as a possible human carcinogen based on the presence of liver tumors found in mice that ingested food contaminated with RDX over a one to two year period [37]. On environmental grounds, replacements for RDX are being sought. While satisfying the stringent environmental regulations, however, it is also a main objective in energetics synthesis labs to develop new secondary explosives that have as much power as possible, while having as little sensitivity as possible.

\subsection{TNT-Free Formulations}

TNT-based explosive fills have historically been ubiquitous in large caliber mortar and artillery munitions. TNT, as discussed previously, is a melt-castable material with a low sensitivity to impact, 
friction and ESD. However, it is not the ideal explosive for insensitive munition applications. TNT is known to exhibit violent behavior when subjected to bullet impact, fire, or when TNT-based artillery and mortar munitions are hit with an improvised explosive device (IED) or rocket-propelled grenade (RPG) [38], putting those in close proximity of an exploding TNT-based round at risk of being seriously injured or killed. This, coupled with the environmental drivers to replace TNT, have led to the development of safer alternatives.

The US Army successfully developed insensitive munitions explosive 101 (IMX-101), which has been fielded to replace the $155 \mathrm{~mm}$ M795 artillery round, with further applications in $105 \mathrm{~mm}$ and $120 \mathrm{~mm}$ munitions. IMX-101 consists of a melt-castable mixture of 2,4-dinitroanisole (DNAN, 41) and nitrotriazolone (NTO, 42) (Figure 4). Unlike TNT-based explosive fills, IMX-101 undergoes only a rapid deflagration rather than a detonation when subjected to fast cook-off, slow cook-off, fragment impact, bullet impact, and sympathetic detonation. TNT failed to pass in all of these categories. Although TNT costs $\$ 6$ per pound, and the DNAN/NTO formulation costs $\$ 8$ per pound, the marginal increase in cost is trivial considering how many lives are likely to be saved in future combat situations [35].

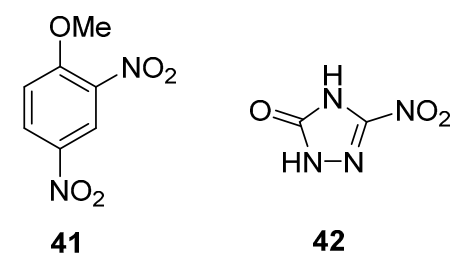

Figure 4. Chemical structures of DNAN (41) and NTO (42).

A well-known TNT-based formulation, which commonly finds use in $60 \mathrm{~mm}, 81 \mathrm{~mm}, 120 \mathrm{~mm}$ and numerous submunitions is the composition B (aka Comp B) formulation. Comp B consists of a melt-castable mixture of TNT and RDX. Comp B is also in the process of being replaced in the aforementioned munitions by insensitive munition explosive 104 (IMX-104), which consists of a melt-castable mixture of DNAN, NTO and RDX. At the time, the IMX-104 formulation has been qualified for use, and it is being evaluated in the aforementioned munitions [39].

\subsection{Potential RDX Replacements}

\subsubsection{TKX-50 (Dihydroxylammonium 5,5'-Bis(tetrazolate) diolate)}

In 2012, Klapötke reported the synthesis of TKX-50 (47), as summarized in Scheme 12 [36,40]. Condensation of glyoxal with hydroxylamine hydrochloride affords glyoxime (43), which is converted to dichlorglyoxime (44) in the presence of chlorine gas in ethanol at cold temperatures.

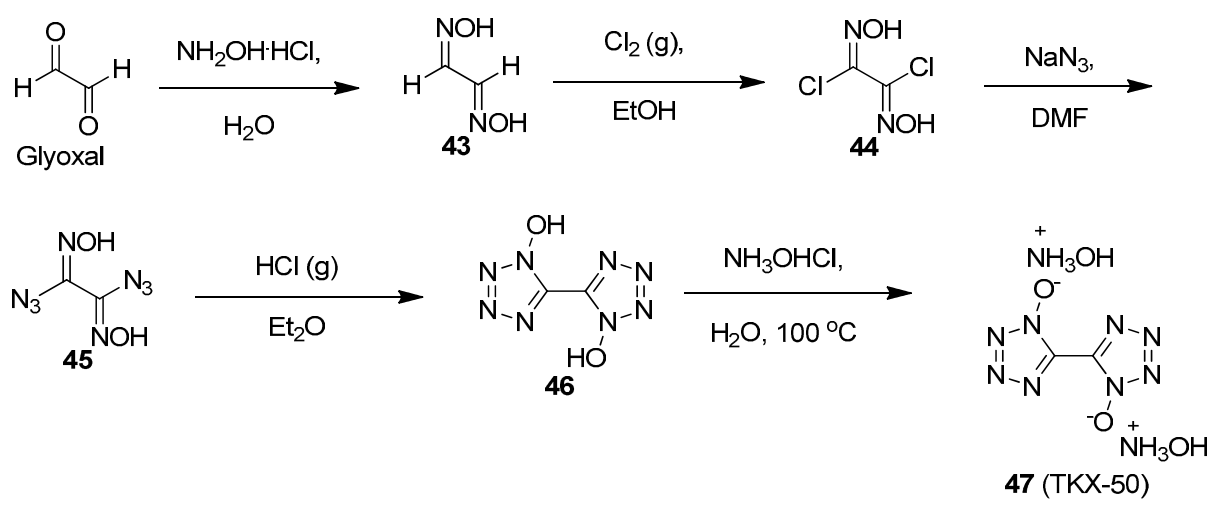

Scheme 12. Synthesis of TKX-50 (47). 
Treatment of (44) with sodium azide produces the highly sensitive diazidoglyoxime intermediate (45), which is treated with $\mathrm{HCl}$ under anhydrous conditions to effect cyclization, thus yielding bis-adjacent tetrazole (46). Exposure of this latter intermediate to dihydroxylammonium chloride results in the formation of TKX-50.

Compared to RDX, TKX-50 was found to have a lower impact sensitivity, with comparable friction and ESD sensitivities. TKX-50 was found to have a higher temperature of decomposition, density, detonation pressure and detonation velocity compared to RDX (Table 6). Due to its reported performance, TKX-50 has been the subject of scale-up and compatibility studies [41]. During that time, efforts by Damavarapu, Paraskos, and Cooke resulted in producing TKX-50 on a $75 \mathrm{~g}$ scale per batch. Over the course of a year, over three pounds of the material was synthesized for testing purposes.

Table 6. Sensitivities and performance of TKX-50 and RDX.

\begin{tabular}{ccc}
\hline Data Category & TKX-50 (47) & RDX \\
\hline IS [J] $^{\mathrm{a}}$ & 20 & 7.5 \\
${\mathrm{FS}[\mathrm{N}]^{\mathrm{b}}}^{\mathrm{b}}$ & 120 & 120 \\
$\mathrm{ESD}^{\mathrm{c}}[\mathrm{J}]^{\mathrm{c}}$ & 0.1 & 0.2 \\
$\mathrm{~T}_{\mathrm{dec}}\left[{ }^{\circ} \mathrm{C}\right]^{\mathrm{d}}$ & 221 & 210 \\
$\Omega_{\mathrm{CO}_{2}[\%]^{\mathrm{e}}}$ & -27.1 & -21.61 \\
$\rho^{\mathrm{g} / \mathrm{cc}]^{\mathrm{f}}}$ & 1.918 & 1.858 \\
$P_{\mathrm{cj}}[\mathrm{kbar}]^{\mathrm{g}}$ & 424 & 380 \\
$V_{\mathrm{det}}[\mathrm{m} / \mathrm{s}]^{\mathrm{h}}$ & 9698 & 8983 \\
$\Delta_{\mathrm{f}} H^{0}[\mathrm{~kJ} / \mathrm{mol}]^{\mathrm{i}}$ & 446.6 & 86.3 \\
$\Delta_{\mathrm{ex}} U^{0}[\mathrm{~kJ} / \mathrm{kg}]^{\mathrm{j}}$ & 6025 & 6190
\end{tabular}

${ }^{\mathrm{a}}$ IS = impact sensitivity; ${ }^{\mathrm{b}} \mathrm{FS}=$ friction sensitivity; ${ }^{\mathrm{c}} \mathrm{ESD}=$ electrostatic discharge; ${ }^{\mathrm{d}} T_{\mathrm{dec}}=$ Temperature of decomposition; ${ }^{\text {e }} \Omega_{\mathrm{CO}_{2}}=\mathrm{CO}_{2}$ oxygen balance; ${ }^{\mathrm{f}} \rho=$ crystalline density; ${ }^{\mathrm{g}} P_{\mathrm{cj}}=$ detonation pressure; ${ }^{\mathrm{h}} V_{\text {det }}=$ detonation velocity; ${ }^{\mathrm{i}} \Delta_{\mathrm{f}} H^{0}=$ molar enthalpy of formation; ${ }^{j} \Delta_{\mathrm{ex}} U^{0}=$ total energy of detonation.

TKX-50 was found to pass the vacuum thermal stability (VTS) test, and thus showed compatibility when combined with a wide range of metals, metal oxides explosive materials, plasticizers, and polymers. One notable exception where VTS failed was when TKX-50 was mixed with the DEMN composition (DEMN is composed of $34.9 \%$ diethylenetriamine trinitrate, $33.4 \%$ ethylenediamine dinitrate, $25.5 \%$ methyl nitroguanidine, and $6.3 \%$ nitroguanidine [42]). Very recent work by Sinditskii has demonstrated that TKX-50 has a burn rate slightly higher than HMX, and that the compound decomposes via dissociation of the salt moiety, producing diammonium 5,5'-bis(tetrazolate) diolate (ABTOX, Figure 5). Sinditskii has also shown that the enthalpy of formation $\left(\Delta_{\mathrm{f}} H^{0}\right)$ of TKX-50 is just $111 \pm 16 \mathrm{~kJ} / \mathrm{mol}$, which is significantly lower than the $\Delta_{\mathrm{f}} H^{0}=446.6 \mathrm{~kJ} / \mathrm{mol}$ that was initially reported, as shown in Table 6 [43].

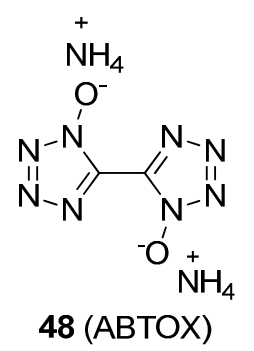

Figure 5. ABTOX (48), a decomposition product of TKX-50.

\subsubsection{Dihydroxylammonium Dinitro-Bis(1,2,4-triazole-1,1'-diolate)}

Shortly after the initial synthesis appeared for TKX-50, Klapötke reported the synthesis of Dihydroxylammonium dinitro-bis-1,2,4-triazole-1,1'-diolate (52) [44]. As outlined in Scheme 13, this 
compound is produced in a four-step process, first by reacting oxalic acid with aminoguanidinium bicarbonate in acidic solution, followed by cyclization upon addition of base to furnish bis(triazole) (49). Introduction of the nitro groups via the Sandmeyer reaction, followed by treatment of the resulting dinitro bis(triazole) (50) oxone, afforded diol (51). Exposure of the diol to hydroxylamine afforded dihydroxylammonium salt (52).

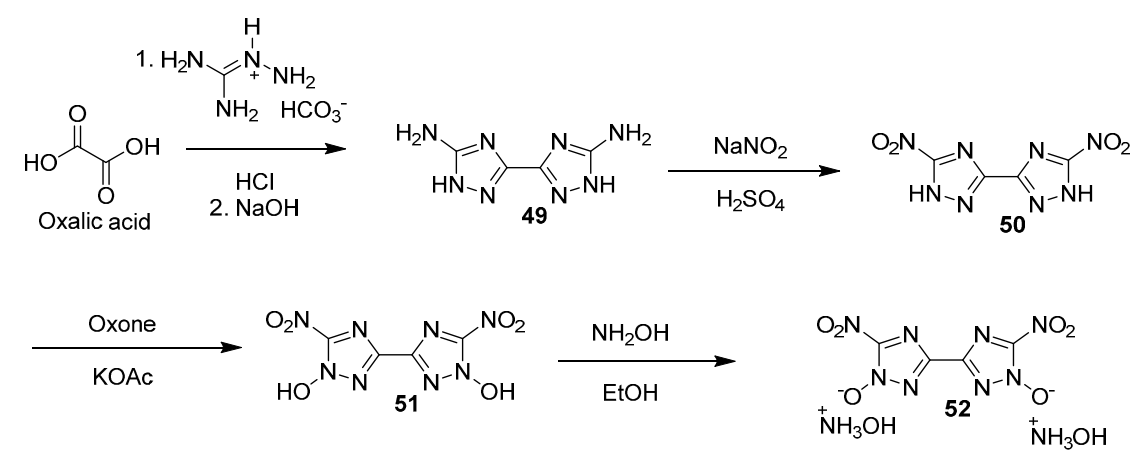

Scheme 13. Synthesis of Dihydroxylammonium dinitro-bis(1,2,4-triazole-1,1'-diolate) (52).

Dihydroxylammonium salt (52) shows a remarkably low sensitivity toward impact, friction, and ESD (Table 7). The explosive performance of this compound appears to be very similar to RDX. Curiously, the enthalpy of formation of dihydroxylammonium salt (52) is significantly lower than the initial reported value for TKX-50, despite the presence of two nitro groups in the structure of the former compound. With the exception of the nitro groups present on (52), these two compounds have many similarities in their structure. It would be expected that the presence of nitro groups should lead to a more positive enthalpy of formation. Therefore, it is plausible that the work carried out by Sinditskii may be valid, and that the original values for TKX-50 may need to be re-evaluated. As one would expect, dihydroxylammonium salt (52) had a higher enthalpy of formation $\left(\Delta_{\mathrm{f}} H^{0}=213 \mathrm{~kJ} / \mathrm{mol}\right)$ than Sinditskii's adjusted value for TKX-50 $\left(\Delta_{\mathrm{f}} H^{0}=111 \pm 16 \mathrm{~kJ} / \mathrm{mol}\right)$.

Table 7. Sensitivities and performance of Dihydroxylammonium salt 52 and RDX.

\begin{tabular}{ccc}
\hline Data Category & $\mathbf{5 2}$ & RDX \\
\hline${\text { IS }[\mathrm{J}]^{\mathrm{a}}}^{\mathrm{F}}$ & 40 & 7.5 \\
${\mathrm{FS}[\mathrm{N}]^{\mathrm{b}}}^{\mathrm{E}}$ & $>360$ & 120 \\
$\mathrm{ESD}^{\mathrm{c}}[\mathrm{J}]^{\mathrm{c}}$ & 0.5 & 0.2 \\
$T_{\mathrm{dec}}\left[{ }^{\circ} \mathrm{C}\right]^{\mathrm{d}}$ & 217 & 210 \\
$\Omega_{\mathrm{CO}_{2}[\%]^{\mathrm{e}}}$ & -19.7 & -21.61 \\
$\rho^{\mathrm{g} / \mathrm{gc}]^{\mathrm{f}}}$ & 1.9 & 1.858 \\
$P_{\mathrm{cj}}[\mathrm{kbar}]^{\mathrm{g}}$ & 390 & 380 \\
$V_{\mathrm{det}}[\mathrm{m} / \mathrm{s}]^{\mathrm{h}}$ & 9087 & 8983 \\
$\Delta_{\mathrm{f}} H^{0}[\mathrm{~kJ} / \mathrm{mol}]^{\mathrm{i}}$ & 213 & 86.3 \\
$\Delta_{\mathrm{ex}} U^{0}[\mathrm{~kJ} / \mathrm{kg}]^{\mathrm{j}}$ & 5985 & 6190 \\
\hline
\end{tabular}

${ }^{\mathrm{a}}$ IS = impact sensitivity; ${ }^{\mathrm{b}} \mathrm{FS}=$ friction sensitivity; ${ }^{\mathrm{c}}$ ESD $=$ electrostatic discharge $;{ }^{\mathrm{d}} T_{\mathrm{dec}}=$ Temperature of decomposition; ${ }^{\mathrm{e}} \Omega_{\mathrm{CO}_{2}}=\mathrm{CO}_{2}$ oxygen balance; ${ }^{\mathrm{f}} \rho=$ crystalline density; ${ }^{\mathrm{g}} P_{\mathrm{cj}}=$ detonation pressure; ${ }^{\mathrm{h}} V_{\text {det }}=$ detonation velocity; ${ }^{\mathrm{i}} \Delta_{\mathrm{f}} H^{0}=$ molar enthalpy of formation; ${ }^{\mathrm{j}} \Delta_{\mathrm{ex}} U^{0}=$ total energy of detonation.

\subsubsection{Nitryl Cyanide $\left(\mathrm{NCNO}_{2}\right)$}

Though a simple molecule on paper, the synthesis of nitryl cyanide proved to be elusive for decades. However, Christe solved this long-standing problem, finally synthesizing this material, and providing full characterization upon isolation [45]. However, the synthesis of nitryl cyanide requires specialized equipment at this time, which is a drawback. Nitryl cyanide was prepared by reacting tert-butyldimethylsilyl cyanide (TBSCN) with nitronium tetrafluoroborate in nitromethane 
at $-30^{\circ} \mathrm{C}$ (Scheme 14). Employing TBSCN in excess resulted in dramatically reduced yields, as well as the formation of cyanogen. Cyanogen is believed to form from a reaction involving TBSCN and nitryl cyanide.

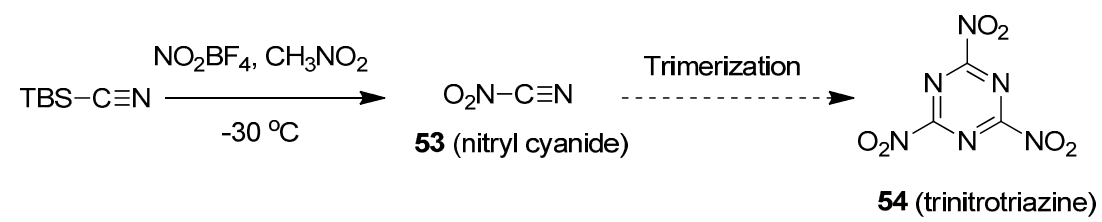

Scheme 14. Synthesis of nitryl cyanide (53) and its proposed trimerization to trinitrotriazine (54).

To reduce the amount of cyanogen formed, TBSCN needs to be condensed at $-196{ }^{\circ} \mathrm{C}$ above a frozen mixture of nitronium tetrafluoroborate in nitromethane. This mixture must be thawed, and only small amounts of TBSCN can be dissolved in the mixture at a time. The reaction by-products from the reaction are TBSF and boron trifluoride $\left(\mathrm{BF}_{3}\right)$, which are removed by fractional condensation through a series of cold traps. Removal of $\mathrm{BF}_{3}$ is critical, as it will readily react with nitryl cyanide in the liquid phase, and this transformation dramatically reduces yields.

Pure nitryl cyanide was found to be a stable liquid at room temperature. It undergoes very little decomposition when heated to $50^{\circ} \mathrm{C}$ or $100^{\circ} \mathrm{C}$ for an hour, but decomposes readily over the course of several hours at $140^{\circ} \mathrm{C}$. Nitryl cyanide is not compatible with fluorides, Lewis acids, bases, amines, $\mathrm{K}_{3} \mathrm{PO}_{4}$, and elemental mercury.

Although not useful on its own as an RDX replacement, trimerization of nitryl cyanide would yield trinitrotriazine (54); an elusive theoretical compound with a predicted density of $1.99 \mathrm{~g} / \mathrm{cc}$, a detonation pressure of $421 \mathrm{kbar}$, and a detonation velocity of $9770 \mathrm{~m} / \mathrm{s}$. Though the sensitivity of trinitrotriazine is not known, the high theoretical performance makes synthesizing this target attractive.

\subsubsection{2,6-Diamino-3,5-Dinitropyrazine- $N$-Oxide (LLM-105)}

LLM-105, initially synthesized at Lawrence Livermore National Laboratories by Pagoria and co-workers in 1994, is an insensitive secondary explosive material with $80 \%$ of the power of HMX. LLM-105 possesses a density of $1.918 \mathrm{~g} / \mathrm{cc}$, a detonation velocity of $8730 \mathrm{~m} / \mathrm{s}$, a detonation pressure of 35.9 GPa, a high thermal decomposition temperature in excess of $350{ }^{\circ} \mathrm{C}$, and very low sensitivities to impact, friction, and electrostatic discharge. The most efficient synthesis to-date developed for LLM-105 is summarized in Scheme 15 [46]. Diaminopyrazine $N$-oxide (DAPO, 57) can be prepared by treating $N$-chloro bis(cyanomethyl) amine (55) or $N$-nitroso bis(cyanomethyl) amine (56) with triethylamine. Reaction of the former compound proceeds in $14 \%$ yield, whereas reaction of the latter compound is $66 \%$. Mixed acid nitration of DAPO affords LLM-105 in a reasonable yield of $64 \%$. Very recent efforts by Zuckerman have detailed some success at synthesizing LLM-105 using a flow microreactor synthesis [47]. Although no increases in yield were realized compared to traditional synthetic processes, reduced reaction times, higher purities, and an increase in safety to the operator have been demonstrated.

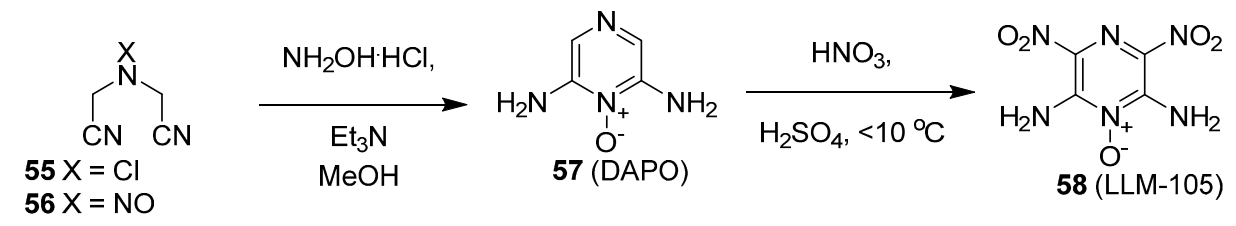

Scheme 15. Synthesis of LLM-105 (58). 


\subsubsection{Energetic co-Crystallization of HMX and CL-20}

In a recent new development in applying pharmaceutical applications to the field of energetic materials, Matzger pioneered the concept of developing the first known energetic co-crystals. The most successful energetic co-crystal reported to date was developed by co-crystallizing a 2:1 molar mixture of CL-20 (39) and HMX (40), whose individual structures are provided in Figure 4 [48]. Surprisingly, the co-crystallized material was shown to have a low impact sensitivity comparable to HMX rather than CL-20, which is believed to be attributed to the high degree of $\mathrm{C}-\mathrm{H}$ bonding interactions present in the co-crystal. These interactions are absent from CL-20 and HMX in their individual, pure form. The co-crystal has a crystalline density of $1.945 \mathrm{~g} / \mathrm{cc}$, was also theoretically predicted to have a detonation velocity of $9484 \mathrm{~m} / \mathrm{s}$, which is higher than $\operatorname{HMX}\left(V_{\text {det }}=9100 \mathrm{~m} / \mathrm{s}\right)$, and undergoes decomposition at $235{ }^{\circ} \mathrm{C}$, followed by detonation at $240{ }^{\circ} \mathrm{C}$. Friction sensitivity, ESD sensitivity, and detonation pressure values were not reported. In future years, as the technology becomes more mature, it will be interesting to determine whether an energetic co-crystal, such as the aforementioned example, will maintain its integrity, structure and power when used in explosive formulations, when subjected to high loading pressures, and when stored in high temperature/high humidity environments for long periods of time.

\subsection{High-Performing Melt-Castable Materials}

\subsubsection{2,3-Dinitro-2,3-Bis((nitrooxy)methyl)Butane-1,4-Diyl Dinitrate}

Melt-castable materials are preferred over press-cured materials due to their less labor-intensive processes, as well as their enhanced safety issues. There is also an increasing interest in the development of melt-castable materials that demosntrate performance exceeding TNT. Work at Los Alamos National Laboratory spearheaded by Chavez led to the synthesis of a new melt-castable material that appears to satisfy these requirements, as summarized in Scheme 16 [49]. Commercially available (though expensive) dioxane (59) was homocoupled to yield dinitro derivative (60). Removal of the diacetal, followed by exhaustive nitration of the resulting tetrol afforded 2,3-Dinitro-2,3-bis((nitrooxy)methyl)butane-1,4-diyl dinitrate (62).

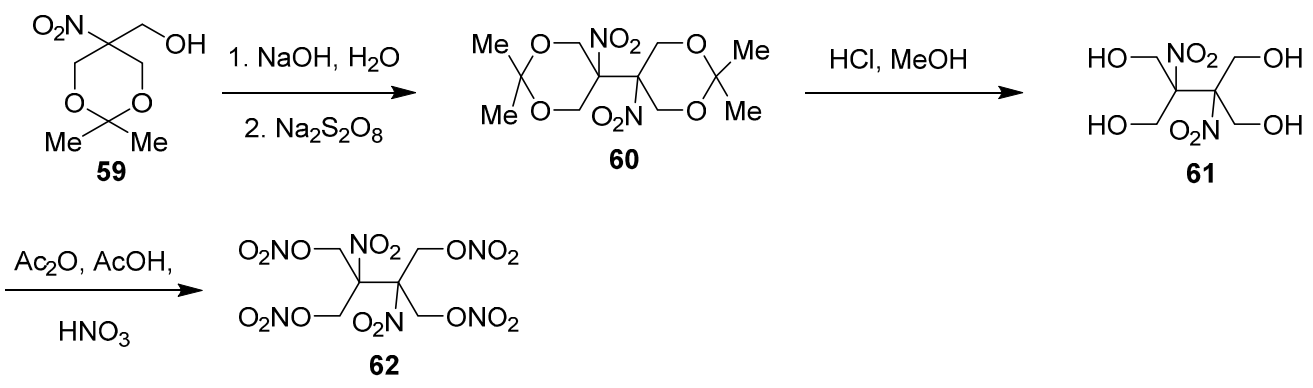

Scheme 16. Synthesis of dinitro tetranitrate ester (62).

This material melts at $85-86^{\circ} \mathrm{C}$, but does not decompose until $141^{\circ} \mathrm{C}$ (Table 8 ). The detonation velocity of tetranitrate ester 62 was calculated to be identical to HMX $(9100 \mathrm{~m} / \mathrm{s})$ with a calculated detonation pressure of $400 \mathrm{kbar}\left(P_{\mathrm{cj}}\right.$ of $\left.\mathrm{HMX}=393 \mathrm{kbar}\right)$. The impact, friction, and ESD sensitivity of this material was found to be comparable to pentaerythritol tetranitrate (PETN). 
Table 8. Performance and sensitivities of tetranitrate ester 62.

\begin{tabular}{cc}
\hline Data Category & $\mathbf{6 2}$ \\
\hline IS [J] ${ }^{\mathrm{a}}$ & 2.7 \\
$\mathrm{FS}[\mathrm{N}]^{\mathrm{b}}$ & 74.5 \\
$\mathrm{ESD}^{\mathrm{c}}[\mathrm{J}]^{\mathrm{c}}$ & 0.625 \\
$T_{\text {melt }}\left[{ }^{\circ} \mathrm{C}\right]^{\mathrm{d}}$ & $85-86$ \\
$T_{\mathrm{dec}}\left[{ }^{\circ} \mathrm{C}\right]^{\mathrm{e}}$ & 140 \\
$\Omega_{\mathrm{CO}_{2}[\%]^{\mathrm{f}}}$ & 0 \\
$\rho[\mathrm{g} / \mathrm{cc}]^{\mathrm{g}}$ & 1.917 \\
$P_{\mathrm{cj}}[\mathrm{kbar}]^{\mathrm{h}}$ & 400 \\
$V_{\mathrm{det}}[\mathrm{m} / \mathrm{s}]^{\mathrm{i}}$ & 9100 \\
$\Delta_{\mathrm{f}} H^{0}[\mathrm{~kJ} / \mathrm{mol}]^{\mathrm{j}}$ & -371
\end{tabular}

${ }^{\mathrm{d}} T_{\text {melt }}=$ Tempterature of melting; ${ }^{\mathrm{e}} T_{\mathrm{dec}}=$ Temperature of decomposition; ${ }^{\mathrm{f}} \Omega_{\mathrm{CO}_{2}}=\mathrm{CO}_{2}$ oxygen balance; g $\rho=$ crystalline density; ${ }^{\mathrm{h}} P_{\mathrm{cj}}=$ detonation pressure; ${ }^{\mathrm{i}} V_{\mathrm{det}}=$ detonation velocity; ${ }^{\mathrm{j}} \Delta_{\mathrm{f}} H^{0}=$ molar enthalpy of formation.

\subsubsection{3,4-Bis(4-nitro-1,2,5-oxadiazol-3-yl)-1,2,5-Oxadiazole-N-Oxide (BNFF, DNTF)}

BNFF (aka DNTF) can be synthesized depicted in Scheme 17 [50]. Formation of furazan (63) from malononitrile, followed by diazotization and substitution furnished chloroxime (64). Exposure of the chloroxime to silver carbonate afforded difurazano furoxan (65), which was nitrated to yield BNFF (66).
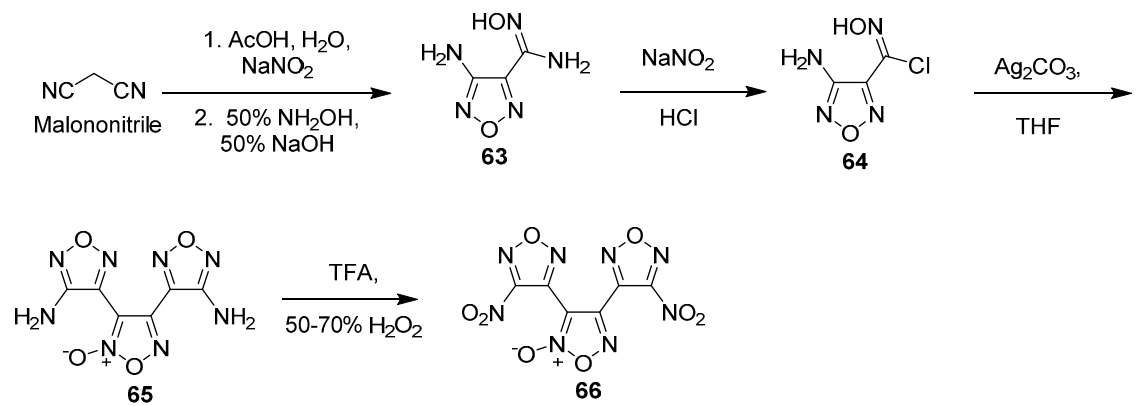

Scheme 17. Synthesis of BNFF (66).

The performance parameters of BNFF, as reported by Sinditskii, are provided in Table 6 [51]. It is worth noting that there are two exothermic events during the decomposition of BNFF, with the first taking place at $292{ }^{\circ} \mathrm{C}$, and the second taking place at $310{ }^{\circ} \mathrm{C}$. Although reported densities of $\mathrm{BNFF}$ are north of $1.90 \mathrm{~g} / \mathrm{cc}$, these are likely at cold temperatures, as the density reported in Table 6 is the experimentally determined density at room temperature. The detonation velocity, enthalpy of formation, and detonation energy values of BNFF detailed in Table 9 represent experimentally determined values.

Table 9. Performance and sensitivities of BNFF.

\begin{tabular}{cc}
\hline Data Category & BNFF (66) \\
\hline$T_{\text {melt }}\left[{ }^{\circ} \mathrm{C}\right]^{\mathrm{a}}$ & $109-111$ \\
$T_{\mathrm{dec}}\left[{ }^{\circ} \mathrm{C}\right]^{\mathrm{b}}$ & 292 \\
$\rho[\mathrm{g} / \mathrm{cc}]^{\mathrm{c}}$ & 1.875 \\
$V_{\mathrm{det}}[\mathrm{m} / \mathrm{s}]{ }^{\mathrm{d}}$ & 8930 \\
$\Delta_{\mathrm{f}} H^{0}[\mathrm{~kJ} / \mathrm{mol}]^{\mathrm{e}}$ & 657.23 \\
$\Delta_{\mathrm{ex}} U^{0}[\mathrm{~kJ} / \mathrm{kg}]^{\mathrm{f}}$ & 5797 \\
\hline perature; $^{\mathrm{b}} T_{\text {dec }}=$ temperature of decomposition; ${ }^{\mathrm{c}} \rho=$ crystalline density; &
\end{tabular}

\footnotetext{
a $T_{\text {melt }}=$ melting temperature; ${ }^{\mathrm{b}} T_{\mathrm{dec}}=$ temperature of decomposition; ${ }^{\mathrm{c}} \rho=$ crystalline de
${ }^{\mathrm{d}} V_{\text {det }}=$ detonation velocity;
} 


\subsubsection{3,4-Bis(4-nitro-1,2,5-oxadiazol-3-yl)-1,2,5-Oxadiazole (LLM-172, BNFF-1)}

A close molecular derivative of BNFF is LLM-172 (aka BNFF-1), as shown in Figure 6. The only difference existing in the structure is that BNFF has the presence of an $\mathrm{N}$-oxide moiety, whereas LLM-172 does not. As summarized in Table 10, LLM-172 has a melting point of $85^{\circ} \mathrm{C}$, which is significantly lower than the melting point of DNTF, thus shifting the former material further into the melt-castable range [52]. Predictably, due to the absence of the $N$-oxide functionality, the performance of LLM-172 is lower than that of DNTF, yet the material also has reduced sensitivity to ignition stimuli as well.<smiles>O=[N+]([O-])c1nonc1-c1nonc1-c1nonc1[O+]</smiles>

Figure 6. Molecular structure of LLM-172 (67).

Table 10. Performance and sensitivities of LLM-172 (67).

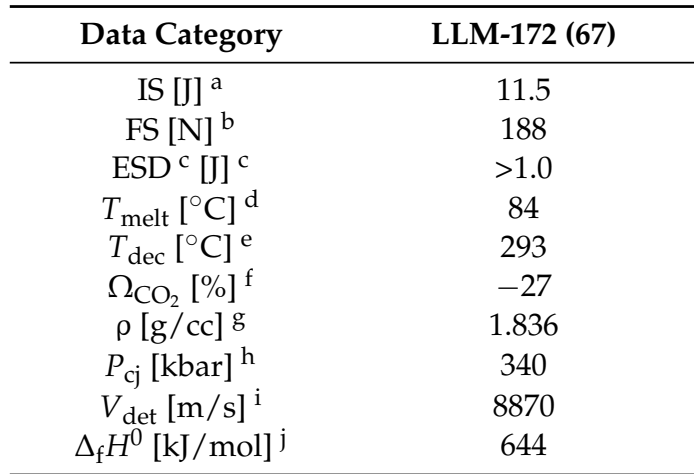

${ }^{\mathrm{a}}$ IS = impact sensitivity; ${ }^{\mathrm{b}} \mathrm{FS}=$ friction sensitivity; ${ }^{\mathrm{c}}$ ESD $=$ electrostatic discharge $;{ }^{\mathrm{d}} T_{\text {melt }}=$ Tempterature of melting; ${ }^{\mathrm{e}} T_{\mathrm{dec}}=$ Temperature of decomposition; ${ }^{\mathrm{f}} \Omega_{\mathrm{CO}_{2}}=\mathrm{CO}_{2}$ oxygen balance; ${ }^{\mathrm{g}} \rho=$ crystalline density; ${ }^{\mathrm{h}} P_{\mathrm{cj}}=$ detonation pressure; ${ }^{\mathrm{i}} V_{\mathrm{det}}=$ detonation velocity; ${ }^{\mathrm{j}} \Delta_{\mathrm{f}} H^{0}=$ molar enthalpy of formation.

\subsubsection{3-(4-Amino-1,2,5-Oxadiazol-3-yl)-4-(4-Nitro-1,2,5-Oxadiazol-3-yl)-1,2,5-Oxadiazole (ANFF-1)}

A final furazan-based compound that is of interest for melt-castable applications is ANFF-1, whose preferred method of synthesis is given in Scheme 18 [53]. BAFF-1 (68) is treated with sulfuric acid and hydrogen peroxide to produce the asymmetrical ANFF-1 via the conversion of one of the two amino groups to a nitro group.<smiles>Nc1nonc1-c1nonc1-c1nonc1N</smiles>

68

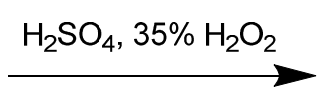<smiles>Nc1nonc1-c1nonc1-c1nonc1[N+](=O)[O-]</smiles>

69

Scheme 18. Synthesis of ANFF-1 (69).

The high density, low melting point, and low level of sensitivity, as outlined in Table 11, makes ANFF-1 a candidate molecule that ought to be explored for further explosive development. 
Table 11. Performance and sensitivities of ANFF-1 (69).

\begin{tabular}{cc}
\hline Data Category & ANFF-1 (69) \\
\hline IS [J] ${ }^{\mathrm{a}}$ & 43.4 \\
$\mathrm{FS}[\mathrm{N}]^{\mathrm{b}}$ & $>353$ \\
$T_{\mathrm{melt}}\left[{ }^{\circ} \mathrm{C}\right]^{\mathrm{d}}$ & 100 \\
$\Omega_{\mathrm{CO}_{2}[\%]^{\mathrm{f}}}$ & -27 \\
$\rho[\mathrm{g} / \mathrm{cc}]^{\mathrm{g}}$ & 1.782 \\
\hline
\end{tabular}

${ }^{\mathrm{a}}$ IS = impact sensitivity; $\overline{\mathrm{b}} \overline{\mathrm{FS}=\text { friction sensitivity; }{ }^{\mathrm{d}} T_{\text {melt }}=\text { Tempterature of melting; }} ;{ }^{\mathrm{f}} \Omega_{\mathrm{CO}_{2}}=\mathrm{CO}_{2}$ oxygen balance; $\mathrm{g} \rho=$ crystalline density.

\section{Conclusions}

For many of the primary and secondary explosive materials discussed in this review, it will be interesting to follow their progress in future years, as many of these ingredients move past the basic research area, and progress into an applied research setting to be investigated in various formulations. While this review is by no means a complete list of explosive ingredients that exist with potential applications, it is felt that the materials described are the most relevant on the bases of performance, synthetic utility, cost, and environmental considerations. It is critical that new energetic materials continue to be synthesized with these aforementioned bases in mind to ensure that what is being made can be used in practical applications.

Acknowledgments: The authors are indebted to Brian D. Roos (ARL) and Noah Lieb (Hughes Associates, Inc.) for many insightful discussions pertaining to this review. Thomas M. Klapötke is gratefully acknowledged for his invitation in submitting this article. The authors thank the US Army Research Laboratory (ARL), the Armaments Research, Development \& Engineering Center (ARDEC), the Research, Development \& Engineering Command (RDECOM) and the Ordnance Environmental Program (OEP) for funding of this work.

Author Contributions: Jesse J. Sabatini and Karl D. Oyler contributed equally to this article.

Conflicts of Interest: The authors declare no conflict of interest.

\section{References}

1. Davis, T.L. The Chemistry of Powder and Explosives; GSG \& Associates: San Pedro, CA, USA, 1943.

2. Klapötke, T.M. Chemistry of High-Energy Materials, 2nd ed.; Walter de Gruyter GmbH \& Co.: Berlin, Germany, 2012.

3. Pagoria, P.F.; Lee, G.S.; Mitchell, A.R.; Schmidt, R.D. A review of energetic materials synthesis. Thermochim. Acta 2002, 384, 187-204. [CrossRef]

4. Badgujar, D.M.; Talawar, M.B.; Asthana, S.N.; Mahulikar, P.P. Advances in science and technology of modern energetic materials: An overview. J. Hazard. Mater. 2008, 151, 289-305. [CrossRef] [PubMed]

5. Singh, R.P.; Gao, H.; Meshri, D.T.; Shreeve, J.M. Nitrogen-rich heterocycles. Struct. Bonding 2007, 125, 35-83.

6. Brede, U.; Hagel, R.; Redecker, K.H.; Weuter, W. Primer compositions in the course of time: From black powder and sinoxid to sintox compositions and sinco booster. Propellants Explos. Pyrotech. 1996, 21, 113-117. [CrossRef]

7. Nobel, A. Improved explosive and primer for the same. Dynamite. British Patent 1345, 7 May 1867.

8. Matyáš, R.; Pachman, J. Primary Explosives; Springer: Heidelberg, Germany, 2013.

9. Herz, E. Lead salt of trinitroresorcin. British Patent 17961, 29 October 1915.

10. Federoff, B.T. Encyclopedia of Explosives and Related Items; Picatinny Arsenal: Dover, NJ, USA, 1960; Volume 1.

11. Committee on Measuring Lead in Critical Populations; Commission on Life Sciences; Division on Earth and Life Studies; National Research Council. Measuring Lead Exposure in Infants, Children, and Other Sensitive Populations; The National Academies Press: Washington, DC, USA, 1993.

12. Clinton, W.J. Executive order 12856 -Federal compliance with right-to-know laws and pollution prevention requirements; Office of the Federal Register: Washington, DC, USA, 1993.

13. Dorman, D.C.; Benoff, S.H.; Bishop, E.C.; Bleecker, M.L.; Brosseau, L.M.; Goldman, R.H.; Graziano, J.H.; Milz, S.A.; Park, S.K.; Roberts, M.A.; et al. National Research Council Report: Potential Health Risks to Dod Firing-Range Personnel from Recurrent Lead Exposure; The National Academies Press: Washington, DC, USA, 2012. 
14. Gilligan, W.H.; Kamlet, M.J. Synthesis of Mercuric 5-Nitrotetrazole; NSWC/WOL/TR 76-146; Naval Surface Weapons Center, White Oak Laboratory: Silver Spring, MD, USA, 1976.

15. Kast, H.; Haid, A. The explosive properties of the most important initiating explosives. Angew. Chem. 1924, 38, 43-52. [CrossRef]

16. Taylor, C.A.; Rinkenbach, W.H. Preparation and Detonating Qualities of Cyanuric Triazide; Reports of Investigation; U.S. Dept. of the Interior, Bureau of Mines: Washington, DC, USA, 1923.

17. Ott, E. Explosive and process of making same. U.S. Patent 1390378, 3 November 1921.

18. Mehta, N.; Cheng, G.; Cordaro, E.A.; Dolch, T.; Yang, K.; Stec, D. Modified Ardec Triazine Triazide (TTA) Synthesis; ARMET-TR-09019; U.S. Army ARDEC: Picatinny, NJ, USA, 2009.

19. Sandstrom, J.; Quinn, A.A.; Erickson, J. Non-toxic, heavy-metal free sensitized explosive percussion primers and methods of preparing the same. U.S. Patent 20110239887, 6 October 2011.

20. Bjerke, R.K.; Ward, J.P.; Ells, D.O.; Kees, K.P. Improved primer composition. U.S. Patent 4963201, 16 October 1990.

21. Erickson, J.A. Lead-free centerfire primer with DDNP and barium nitrate oxidizer. U.S. Patent 5831208, 3 November 1998.

22. Gamage, N.-D.H.; Stiasny, B.; Stierstorfer, J.; Martin, P.D.; Klapötke, T.M.; Winter, C.H. Less sensitive oxygen-rich organic peroxides containing geminal hydroperoxy groups. Chem. Commun. 2015, 51, 13298-13300. [CrossRef] [PubMed]

23. Fronabarger, J.W.; Williams, M.D. Alternative to tetrazene. U.S. Patent 8524019, 3 September 2013.

24. Yan, Q.-L.; Zeman, S.; Zhang, J.-G.; He, P.; Musil, T.; Bartoskova, M. Multi-stage decomposition of 5-aminotetrazole derivatives: Kinetics and reaction channels for the rate-limiting steps. Phys. Chem. Chem. Phys. 2014, 16, 24282-24291. [CrossRef] [PubMed]

25. Costain, T. Investigation of Potassium Dinitrobenzofuroxan (KDNBF) to Provide Data Necessary for the Preparation of a Military Specification; Picatinny Arsenal: Picatinny, NJ, USA, 1970.

26. Fronabarger, J.W.; Williams, M.D.; Sanborn, W.B.; Parrish, D.A.; Bichay, M. KDNP-A lead free replacement for lead styphnate. Propellants Explos. Pyrotech. 2011, 36, 459-470. [CrossRef]

27. Fischer, D.; Klapötke, T.M.; Stierstorfer, J. Potassium 1,1'-dinitramino-5,5'-bistetrazolate: A primary explosive with fast detonation and high initiation power. Angew. Chem. Int. Edit. 2014, 53, 8172-8175. [CrossRef] [PubMed]

28. Fischer, D.; Klapötke, T.M.; Stierstorfer, J. 1,5-di(nitramino)tetrazole: High sensitivity and superior explosive performance. Angew. Chem. Int. Edit. 2015, 54, 10299-10302. [CrossRef] [PubMed]

29. Fronabarger, J.W.; Williams, M.D.; Bragg, J.G.; Parrish, D.A.; Bichay, M. DBX-1-A lead-free replacement for lead azide. Propellants Explos. Pyrotech. 2011, 36, 541-550. [CrossRef]

30. Huynh, M.H.V.; Hiskey, M.A.; Meyer, T.J.; Wetzler, M. Green primaries: Environmentally friendly energetic complexes. Proc. Natl. Acad. Sci. USA 2006, 103, 5409-5412. [CrossRef] [PubMed]

31. Klapötke, T.M.; Piercey, D.G.; Mehta, N.; Oyler, K.D.; Sabatini, J.J. Reaction of copper(I) nitrotetrazolate (DBX-1) with sodium m-periodate. Z. Naturforsch. B J. Chem. Sci. 2014, 69, 125-127. [CrossRef]

32. Von Herz, E. C-nitrotetrazole compounds. U.S. Patent 2066954, 5 January 1937.

33. Gilligan, W.H.; Kamlet, M.J. Method of preparing the acid copper salt of 5-nitrotetrazole. U.S. Patent 4093623, 6 June 1978.

34. Ford, D.D.; Lenahan, S.; Jorgensen, M.; Dube, P.; Delude, M.; Concannon, P.E.; Anderson, S.R.; Oyler, K.D.; Cheng, G.; Mehta, N.; et al. Development of a lean process to the lead-free primary explosive DBX-1. Org. Process Res. Dev. 2015, 19, 673-680. [CrossRef]

35. Chapman, R.D.; Hollins, R.A.; Groshens, T.J.; Nissan, D.A. Benzylamine-Free, Heavy-Metal-Free Synthesis of Cl-20; SERDP SEED Project WP-1518; Naval Air Warfare Center Weapons Division China Lake: Lake, CA, USA; 28 December 2006.

36. Bachmann, W.E.; Sheehan, J.C. A new method of preparing the high explosive RDX. J. Am. Chem. Soc. 1949, 71, 1842-1845. [CrossRef]

37. Agency for Toxic Substances and Disease Registry (ATSDR). Toxic substances portal—Cyclonite (RDX). Available online: http://www.atsdr.cdc.gov/toxfaqs/tf.asp?id=411\&tid=72 (accessed on 25 July 2015).

38. Thompson, M. The 50 best inventions of 2010: Less dangerous explosives. Time Magazine, 11 November 2011. Available online: http://content.time.com/time/specials/packages/article/0,28804,2029497_2030613_2029816,00.html (accessed on 29 December 2015). 
39. Fung, V.; Schreiber, B.; Patel, C.; Samuels, P.; Vinh, P.; Zhao, X.-L. Process Improvement and Optimization of Insensitive Explosive IMX-101; Insensitive Munitions \& Energetic Materials Technology Symposium (IMEMTS) \& National Defense Industrial Association (NDIA): Las Vegas, NV, USA, 2012.

40. Fischer, N.; Fischer, D.; Klapötke, T.M.; Piercey, D.G.; Stierstorfer, J. Pushing the limits of energetic materials-The synthesis and characterization of dihydroxylammonium 5,5'-bistetrazole-1,1'-diolate. J. Mater. Chem. 2012, 22, 20418-20422. [CrossRef]

41. Nicolich, S.; Samuels, P.; Damavarapu, R.; Paraskos, A.J.; Cooke, E.; Stepanov, V.; Cook, P.; Caflin, K.; Duddu, R. Dihydroxylammonium 5,5'-bistetrazole-1,1' diolate (TKX-50) synthesis and lab scale characterization. In Proceedings of the Insensitive Munitions Energetic Materials Technology Symposium (IMEMTS), Rome, Italy, 18-21 May 2015; National Defense Industrial Association (NDIA): Rome, Italy.

42. Aubert, S.A.; Roos, B.D. Melt cast insensitive eutectic explosive. U.S. Patent 8663406, 3 March 2014.

43. Sinditskii, V.P.; Filatov, S.A.; Kolesov, V.I.; Kapranov, K.O.; Asachenko, A.F.; Nechaev, M.S.; Lunin, V.V.; Shishov, N.I. Combustion behavior and physico-chemical properties of dihydroxylammonium 5,5'-bistetrazole-1,1'-diolate (TKX-50). Thermochim. Acta 2015, 614, 85-92. [CrossRef]

44. Dippold, A.A.; Klapötke, T.M. A study of dinitro-bis-1,2,4-triazole-1,1'-diol and derivatives: Design of high-performance insensitive energetic materials by the introduction of n-oxides. J. Am. Chem. Soc. 2013, 135, 9931-9938. [CrossRef] [PubMed]

45. Rahm, M.; Bèlanger-Chabot, G.; Haiges, R.; Christe, K.O. Nitryl cyanide, $\mathrm{NCNO}_{2}$. Angew. Chem. Int. Ed. 2014, 53, 6893-6897. [CrossRef] [PubMed]

46. Pagoria, P.F.; Zhang, M.X. Process for preparation of pyrazines including 2,6-diaminopyrazine-1-oxide (DAPO) and 2,6-diamino-3,5-dinitropyrazine-1-oxide (LLM-105). U.S. Patent 20100267955, 21 October 2010.

47. Zuckerman, N.B.; Shusteff, M.; Pagoria, P.F.; Gash, A.E. Microreactor flow synthesis of the secondary high explosive 2,6-diamino-3,5-dinitropyrazine-1-oxide (LLM-105). In Proceedings of the Insensitive Munitions Energetic Materials Technology Symposium (IMEMTS), Rome, Italy, 18-21 May 2015; National Defense Industrial Association (NDIA): Rome, Italy.

48. Bolton, O.; Simke, L.R.; Pagoria, P.F.; Matzger, A.J. High power explosive with good sensitivity: A 2:1 cocrystal of CL-20:HMX. Cryst. Growth Des. 2012, 12, 4311-4314. [CrossRef]

49. Chavez, D.E.; Hiskey, M.A.; Naud, D.L.; Parrish, D. Synthesis of an energetic nitrate ester. Angew. Chem. Int. Ed. 2008, 47, 8307-8309. [CrossRef] [PubMed]

50. Tsyshevsky, R.; Pagoria, P.; Zhang, M.; Racoveanu, A.; DeHope, A.; Parrish, D.; Kuklja, M.M. Searching for low-sensitivity cast-melt high-energy-density materials: Synthesis, characterization, and decomposition kinetics of 3,4-bis(4-nitro-1,2,5-oxadiazol-3-yl)-1,2,5-oxadiazole-2-oxide. J. Phys. Chem. C 2015, 119, 3509-3521. [CrossRef]

51. Sinditskii, V.P.; Burzhava, A.V.; Sheremetev, A.B.; Aleksandrova, N.S. Thermal and combustion properties of 3,4-bis(3-nitrofurazan-4-yl)furoxan (DNTF). Propellants Explos. Pyrotech. 2012, 37, 575-580. [CrossRef]

52. DeHope, A.; Zhang, M.; Lorenz, K.T.; Lee, E.; Parrish, D.; Pagoria, P.F. Synthesis and small-scale performance characterization of "new" insensitive energetic compounds. In Proceedings of the Insensitive Munitions Energetic Materials Technology Symposium (IMEMTS), Rome, Italy, 18-21 May 2015; National Defense Industrial Association (NDIA): Rome, Italy.

53. Pagoria, P.; Zhang, M.; Racoveanu, A.; DeHope, A.; Tsyshevsky, R.; Kuklja, M.M. 3-(4-Amino-1,2,5-oxadiazol-3-yl)4-(4-nitro-1,2,5-oxadiazol-3-yl)-1,2,5-oxadiazole. Molbank 2014, 2014, M824. [CrossRef]

(C) 2015 by the authors; licensee MDPI, Basel, Switzerland. This article is an open access article distributed under the terms and conditions of the Creative Commons by Attribution (CC-BY) license (http:/ / creativecommons.org/licenses/by/4.0/). 